\title{
Molecular characterization of the missing electron pathways for butanol synthesis in Clostridium acetobutylicum
}

\section{Celine Foulquier}

University of Toulouse

Anntoine Rivière

University of Toulouse

Mathieu Heulot

University of Toulouse

\section{Suzana Dos Reis}

Institut de Pharmacologie et de Biologie Structurale, IPBS, Université de Toulouse, CNRS, UPS, Toulouse

\section{Caroline Perdu}

University of Toulouse

\section{Laurence Girbal}

University of Toulouse

\section{Mailys Pinault}

University of Toulouse

\section{Simon Dusséaux}

University of Toulouse

Philippe Soucaille ( $\nabla$ soucaille@insa-toulouse.fr)

University of Toulouse https://orcid.org/0000-0002-1724-7136

Isabelle Meynial-Salles

Université de Toulouse, INSA, UPS, INP, LISBP, INRA UMR792, CNRS UMR5504, Toulouse

\section{Article}

Keywords: electron pathways, metabolic engineering, butanol

Posted Date: September 16th, 2021

DOI: https://doi.org/10.21203/rs.3.rs-882149/v1

License: (c) (1) This work is licensed under a Creative Commons Attribution 4.0 International License.

Read Full License 
Version of Record: A version of this preprint was published at Nature Communications on August 10th, 2022. See the published version at https://doi.org/10.1038/s41467-022-32269-1. 


\section{Molecular characterization of the missing electron pathways for butanol}

\section{synthesis in Clostridium acetobutylicum}

Céline Foulquier ${ }^{1+}$, Antoine Rivière ${ }^{1+}$, Mathieu Heulot ${ }^{1}$, Suzanna Dos Reis ${ }^{1}$, Caroline Perdu ${ }^{1}$, Laurence Girbal ${ }^{1}$, Mailys Pinault ${ }^{1}$, Simon Dusséaux ${ }^{1}$, Philippe Soucaille ${ }^{1,2^{*}}$ \& Isabelle MeynialSalles ${ }^{1}$

${ }^{\dagger}$ Céline Foulquier and Antoine Rivière contributed equally to this work.

$1 \mathrm{TBI}$, Université de Toulouse, CNRS, INRAE, INSA, Toulouse, France 2 BBSRC/EPSRC Synthetic Biology Research Centre, School of Life Sciences, Centre for Biomolecular Sciences, University of Nottingham, United Kingdom

*Corresponding author: correspondence and material requests should be addressed to soucaille@insa-toulouse.fr 


\section{Abstract:}

Clostridium acetobutylicum is a promising biocatalyst for the production of $n$-butanol at high yield from renewable resources. Several metabolic strategies have already been developed to increase butanol yields, most often based on carbon pathway redirection. However, it was previously demonstrated that the activities of both ferredoxin-NADP ${ }^{+}$reductase and ferredoxin-NAD+ reductase, whose encoding genes remained unknown until this study, were necessary to produce the NADPH and the extra NADH needed for butanol synthesis under solventogenic conditions. Here, we purified, identified and characterized the proteins responsible for both ferredoxin-NADP ${ }^{+}$reductase and ferredoxin-NAD ${ }^{+}$reductase activities and demonstrated the involvement of the identified enzymes in butanol synthesis through a reverse genetic approach. We further demonstrated the yield of butanol formation was limited by the level of expression of $C A C \_0764$, the ferredoxin-NADP ${ }^{+}$reductase encoding gene.

The integration of these enzymes into metabolic engineering strategies introduces new opportunities for developing a homobutanologenic C. acetobutylicum strain. 


\section{Introduction:}

Clostridium acetobutylicum is a gram-positive, spore-forming anaerobic bacterium capable of converting various sugars and polysaccharides to organic acids (acetate and butyrate) and solvents (acetone, butanol, and ethanol). Due to its importance in the industrial production of the bulk chemicals acetone and butanol (1-3) and its potential use in the production of $n$ butanol, a promising biobased liquid fuel with several advantages over ethanol (4-5), much research has focused on i) understanding the regulation of solvent formation (6-15) and ii) metabolically engineering this microorganism to produce high yields of alcohols (16-18).

Using a global system biology approach to the characterization of the solventogenic metabolism of a phosphate-limited chemostat culture of $C$. acetobutylicum, the six steps involved in the conversion of acetyl-CoA to butanol (Fig. 1) were fully characterized (19): the main enzyme responsible for crotonyl-CoA reduction to butyryl-CoA is the BCD complex (encoded by $b c d$, etfA and etfB), a bifurcating enzyme consuming 2 moles of NADH and producing one mole of reduced ferredoxin, and the last two steps of butanol production are catalyzed by AdhE1 through its NADH-dependent aldehyde dehydrogenase activity and by BdhB, BdhC and BdhA through their NADPH-dependent butanol dehydrogenase activity. These results have a strong impact on electron flux distribution, as it was demonstrated that both ferredoxin $\mathrm{NADP}^{+}$reductase and ferredoxin $\mathrm{NAD}^{+}$reductase activities were necessary to produce the NADPH and the extra NADH needed for butanol synthesis from acetyl-CoA (Fig. 2)(19). Although the activities of these enzymes were previously detected in C. acetobutylicum $(6,20)$, the encoding genes remained unknown $(19,21)$. Ferredoxin-NADP ${ }^{+}$reductase enzymes (FNOR) (EC 1.18.1.3) are distributed over a variety of aerobic organisms from prokaryotes to eukaryotes, especially in plants (22), but have never been purified and characterized from any clostridial species. In contrast, ferredoxin-dependent $\mathrm{NAD}^{+}$reduction coupled to proton 
export (Rnf) and ferredoxin-dependent transhydrogenases (Nfn) are of central importance in anaerobic bacteria, as they catalyze electron transfer from reduced ferredoxin to $N A D(P)^{+}$to maintain the redox balance. Although Rnf and $\mathrm{Nfn}$ have been characterized from a molecular perspective in several clostridial species, no homologs have been found in $C$. acetobutylicum (23-25). Moreover, C. acetobutylicum cannot produce NADPH by the oxidative pentosephosphate pathway, as zwf, which encodes glucose-6-P dehydrogenase, the first and key enzyme of this pathway, is missing $(19,26)$.

The aim of this study was to purify and identify the proteins responsible for the ferredoxin$\mathrm{NAD}^{+}$and ferredoxin-NADP ${ }^{+}$reductase activities in $C$. acetobutylicum under solventogenic conditions. We further confirmed their essential physiological role in butanol synthesis in $C$. acetobutylicum and demonstrated that butanol production is limited by the electron flux between reduced ferredoxin and both $\mathrm{NADP}^{+}$and $\mathrm{NAD}^{+}$.

\section{Results:}

Solventogenesis in C. acetobutylicum: biochemical analysis of the glucose to $n$-butanol pathway:

C. acetobutylicum can in theory convert one mole of glucose into one mole of $n$-butanol. The conversion of one mole of glucose to 2 moles of acetyl-CoA is associated with the production of 2 moles of NADH in the EMP pathway and 2 moles of reduced ferredoxin during the decarboxylation of 2 moles of pyruvate to 2 acetyl-CoA using pyruvate ferredoxin oxidoreductase (PFOR) (Fig. 1). However, under solventogenic conditions, the conversion of 2 moles of acetyl-CoA to one mole of $n$-butanol produces one mole of reduced ferredoxin during the reduction of crotonyl-CoA to butyryl-CoA by butyryl-CoA dehydrogenase (BCD) and 
consumes 4 moles of NADH and one mole of NADPH to reduce butyraldehyde to n-butanol

(Fig. 1) by the NADPH-dependent alcohol dehydrogenases BdhB, BdhC and BdhA (19).

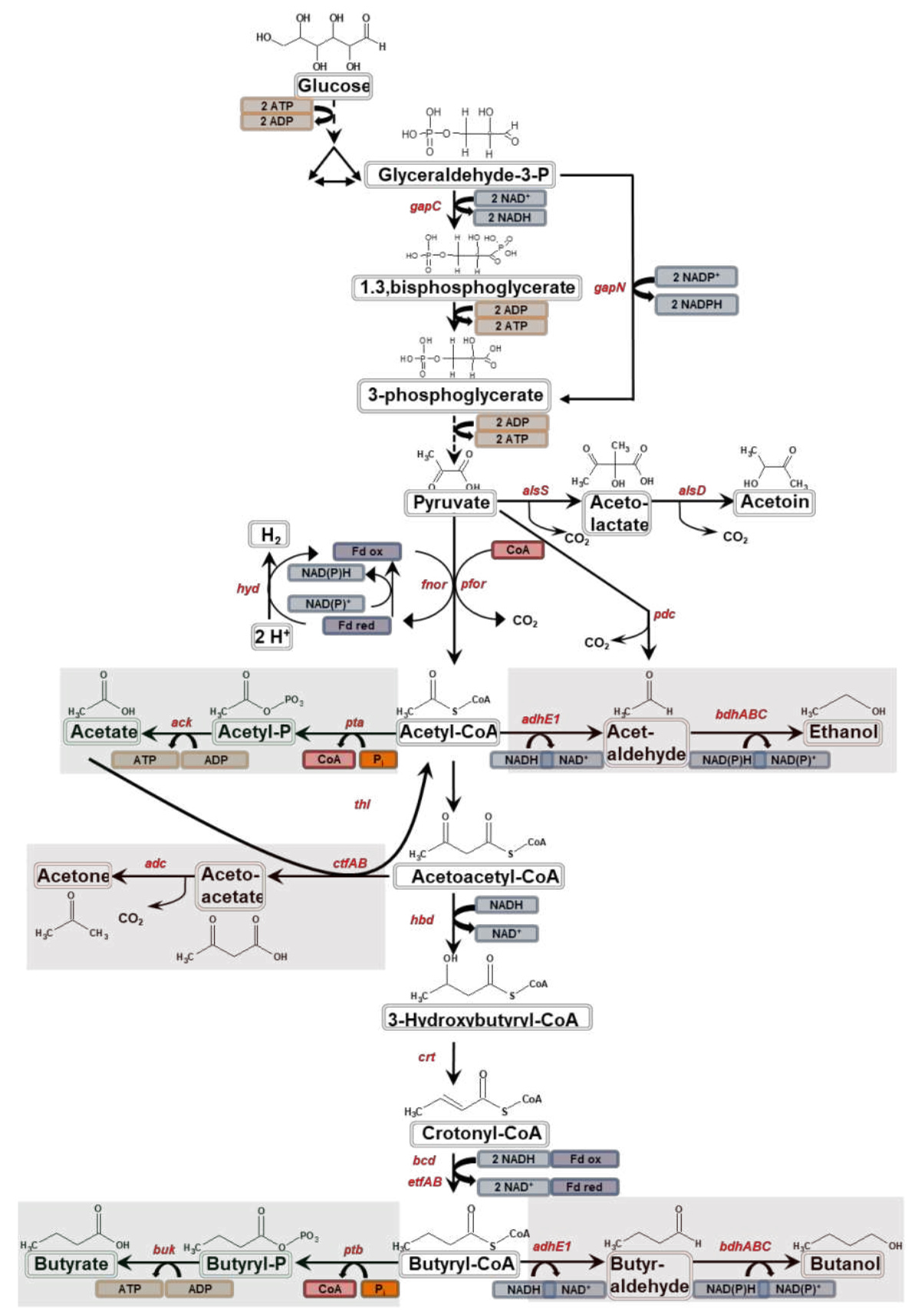

Fig. 1 Central metabolism of Clostridium acetobutylicum. The green box indicates the primary products under acidogenic conditions, whereas the red box indicates the primary products under solventogenic conditions. The letters in red and italics indicate the corresponding genes. Abbreviations: ack, acetate kinase; adc, acetoacetate decarboxylase; adhE1, aldehyde dehydrogenase; adhE2, bifunctional aldehyde/alcohol dehydrogenase; alsD, alphaacetolactate decarboxylase; alsS, acetolactate synthase; bcd, butyryl-CoA dehydrogenase; $b d h$, butanol dehydrogenase; buk, butyrate kinase; crt, crotonase; ctfAB, CoA-transferase; etf, 
electron transfer flavoprotein; $h b d$, 3-hydroxybutyryl-CoA dehydrogenase; hyd, hydrogenase; fnor, ferredoxin-NAD $(\mathrm{P})^{+}$oxidoreductase; $p d c$, pyruvate decarboxylase; pfor, pyruvate:ferredoxin oxidoreductase; pta, phosphotransacetylase; ptb, phosphotransbutyrylase; thl, thiolase; gapC, NADH-dependent glyceraldehyde-3-phosphate dehydrogenase; gapN, nonphosphorylating NADPH-producing glyceraldehyde-3-phosphate dehydrogenase; Fd ox represents oxidized ferredoxin, whereas Fd red represents reduced ferredoxin.

As the EMP pathway produces less NADH than the $n$-butanol pathway consumes, for each mole of $n$-butanol produced, 2 moles of reduced ferredoxin must be used to produce two moles of NADH using a ferredoxin-NAD ${ }^{+}$reductase. Furthermore, as $C$. acetobutylicum does not have an oxidative pentose-phosphate pathway (26) and as the nonphosphorylating NADPH producing glyceraldehyde-3-P dehydrogenase encoded by gapN is expressed at a low level (19), for each mole of $n$-butanol produced, one mole of reduced ferredoxin must also be used to produce one mole of NADPH using a ferredoxin-NADP ${ }^{+}$reductase.

From this analysis, it is clear that ferredoxin-NAD ${ }^{+}$and ferredoxin-NADP ${ }^{+}$reductases are key to providing electrons for the production of n-butanol (Fig. 2), but until now, the proteins involved remained totally unknown. It was therefore decided to purify all the enzymes with ferredoxin-NAD ${ }^{+}$or ferredoxin-NADP ${ }^{+}$reductase activity.
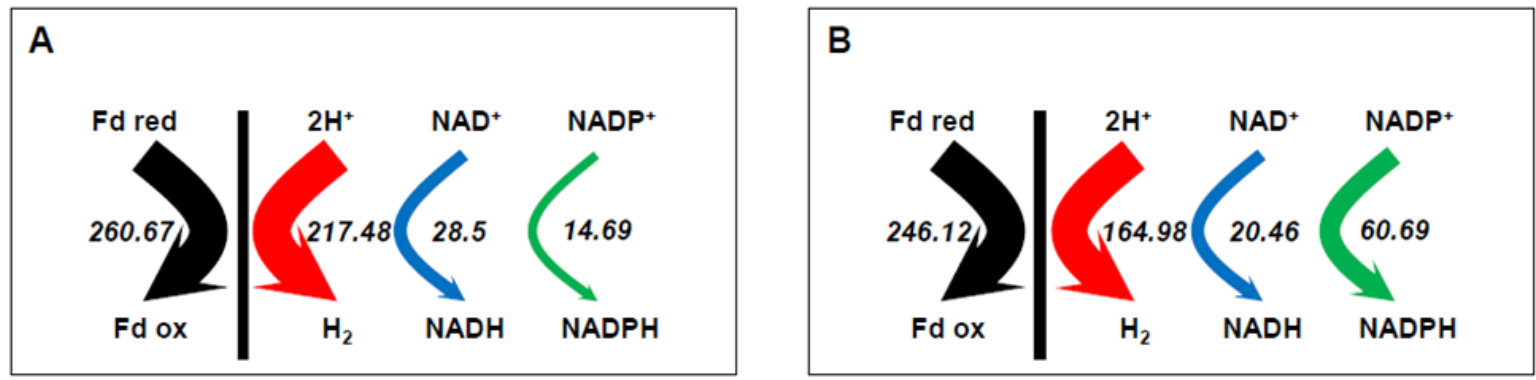

Fig. 2. Metabolic flux analysis of $C$. acetobutylicum in phosphate limited chemostat cultures under acidogenic ( $\mathrm{pH}$ 6.3) (A) and solventogenic $(\mathrm{pH} 4.4)$ (B) conditions. All values ( $\mathrm{mmol} / \mathrm{gDCW} / \mathrm{h}$ ) are normalized to the flux of glucose consumption (19). 


\section{Purification and characterization of the ferredoxin-NADP ${ }^{+}$reductase of $C$. acetobutylicum:}

Proteins with ferredoxin-NADP ${ }^{+}$reductase activities were purified under strict anaerobic conditions from C. acetobutylicum ATCC 824 crude extract as described in the methods. Proteins were first captured using a Capto DEAE matrix, and active eluted fractions were pooled and then purified using a ResourceQ column. After concentration, active eluted fractions were finally loaded onto a Superose 12 column. The results of a traditional purification are presented in Table 1. Activities were measured at $340 \mathrm{~nm}$ by NADP ${ }^{+}$reduction using CAC0303 reduced ferredoxin as the electron donor. During the purification process, the purified enzyme lost $60 \%$ of its activity after 48 hours.

\begin{tabular}{|lcccccc|}
\hline \multicolumn{1}{|c|}{ Table 1 Purification of Ferredoxin } & $\begin{array}{l}\text { NADP } \\
\text { Steps }\end{array}$ & $\begin{array}{c}\text { Activity } \\
\text { (Units) }\end{array}$ & $\begin{array}{c}\text { Protein } \\
\text { (mg) }\end{array}$ & $\begin{array}{c}\text { Specific activity } \\
\text { (units/mg) }\end{array}$ & $\begin{array}{c}\text { Recovery } \\
\text { (\%) }\end{array}$ & $\begin{array}{c}\text { Purification } \\
\text { fold }\end{array}$ \\
\hline Crude extract & 2.7 & 150 & 0.02 & 100 & 1 \\
Streptomycin sulfate supernatant & 2.46 & 104 & 0.02 & 92 & 1.33 \\
CAPTO DEAE column & 0.52 & 1.93 & 0.27 & 20 & 15 \\
Resource Q column & 0.066 & 0.22 & 0.3 & 2.44 & 12.5 \\
Superose 12 column & 0.02 & 0.012 & 1.73 & 0.74 & 96 \\
\hline
\end{tabular}

Active eluted fractions from gel filtration were then subjected to denaturing gel electrophoresis. As shown in Supplementary Fig. 1, the increase in ferredoxin-NADP ${ }^{+}$ reductase activity seems to be linked to the concentration of a protein with an apparent molecular mass of $45 \mathrm{kDa}$ on SDS-PAGE.

The region of the gel corresponding to this protein was eluted, digested by trypsin and analyzed by nano-LC-MS/MS as described in the methods. The encoding gene is CA_CO764, annotated as an NADPH-dependent glutamate synthase beta subunit. Identical treatments were applied to the 40 and $55 \mathrm{kDa}$ proteins, which were identified as thiolase (CA_C2873) and phosphoribosylaminoimidazole carboxamide formyltransferase-IMP cyclohydrolase 
(CA_C1395). None of these proteins are oxidoreductases. The gene identification results were used to extract the quantitative transcriptomic and proteomic data performed by Yoo et al., and it was confirmed that the expression of $C A \_C 0764$ from a monocistronic operon was higher under solventogenic condition than under acidogenic condition (Fig. 3).

A

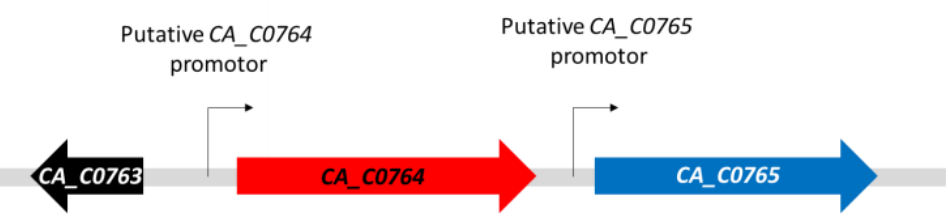

CA_C0764 chromosomic region $4001 \mathrm{bp}$

B

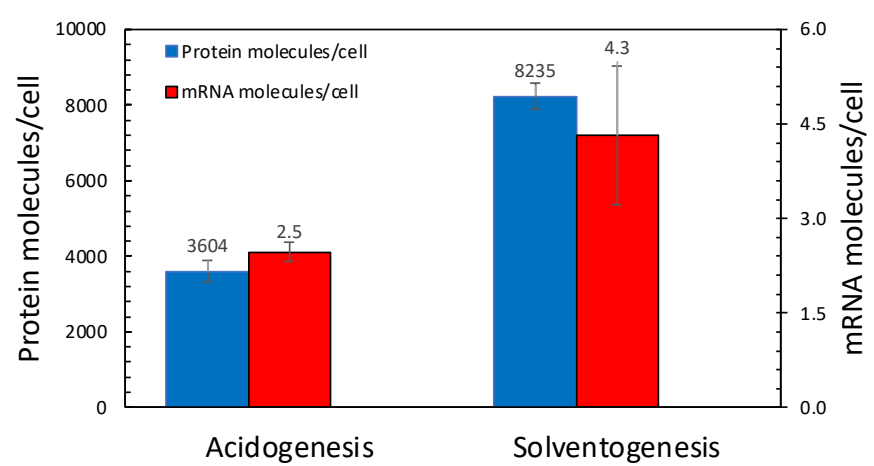

Fig. 3: A: $C A \_C 0764$ chromosomic region of $C$. acetobutylicum. Putative -35 and -10 sequences of CA_C0764 and CA_CO765 were analyzed by the BPROM tool. B: Analysis of CA_CO764 expression under acidogenesis and solventogenesis (19).

To validate the ferredoxin-NADP ${ }^{+}$reductase activity of the CAC0764 protein, the CA_CO764 gene was cloned into a replicative plasmid to be fused with a small tag (Strep-tag II) placed in the C-terminal position of CAC0764, as described in Methods. The recombinant protein was homologously overexpressed in MGC $\triangle \operatorname{cac} 1502$ and then purified from the crude extract in a single step using affinity chromatography on a Strep-Tactin column. Recombinant proteins were eluted with desthiobiotin, and the purity of the eluted fraction was checked by SDS-PAGE with Coomassie blue staining (Supplementary Fig. 2). 
As expected, denaturing gel electrophoresis showed a single band in the eluted fraction corresponding to an apparent molecular mass of $45 \mathrm{kDa}$, demonstrating that CAC0764 was pure.

In vitro ferredoxin $\mathrm{NAD}(\mathrm{P})^{+}$reductase and $\mathrm{NAD}(\mathrm{P}) \mathrm{H}$ ferredoxin reductase activities were evaluated in the recovered pure fraction using NADP ${ }^{+}$reduction with reduced ferredoxin as an electron donor or methyl viologen reduction by NADPH. According to Supplementary Fig. 2, purified CAC0764-Strep-tag II exhibited both NAPDH ferredoxin reductase and ferredoxin$\mathrm{NADP}^{+}$reductase activities, and neither activity was observed in the presence of NADH and $\mathrm{NAD}^{+}$. These results confirmed that CAC0764 is an FNOR enzyme that is strictly NADPH/NADP ${ }^{+}$ dependent.

\section{Purification and characterization of the ferredoxin-NAD+ reductase of $C$. acetobutylicum:}

Proteins with ferredoxin-NAD ${ }^{+}$reductase activities were purified under strict anaerobic conditions from C. acetobutylicum ATCC 824 crude extract as described in the methods. Proteins were first captured using a Capto DEAE matrix and eluted with a linear gradient of $\mathrm{NaCl}$ from 0.1 to $0.25 \mathrm{M}$, yielding two peaks (one minor and one major) of ferredoxin-NAD+ reductase activities. The peak-activity eluted fractions were pooled separately and then concentrated before being finally loaded onto a Superose 12 or a Resource $Q$ column. The results are presented in Table 2.

\begin{tabular}{|lcccccc|}
\hline \multicolumn{2}{|l}{\begin{tabular}{l} 
Table 2: purification of Ferredoxin \\
\multicolumn{1}{|c|}{ Steps }
\end{tabular}} & $\begin{array}{c}\text { Activity } \\
\text { (Units) }\end{array}$ & $\begin{array}{c}\text { Protein } \\
\text { (mg) }\end{array}$ & $\begin{array}{c}\text { Specific activity } \\
\text { (units/mg) }\end{array}$ & $\begin{array}{c}\text { Recovery } \\
\text { (\%) }\end{array}$ & $\begin{array}{c}\text { Purification } \\
\text { fold }\end{array}$ \\
\hline Crude extract & 13.4 & 203 & 0.07 & 100 & 0 \\
Streptomycin sulfate supernatant & & 9.02 & 102 & 0.09 & 67 & 1.28 \\
CAPTO DEAE column & major peak 1 & 7.3 & 5.44 & 1.34 & 54 & 19.14 \\
& minor peak 2 & 1.27 & 4,06 & 0.31 & 9.5 & 4.49 \\
Peak 1 on Superose 12 column & & 3.43 & 1.5 & 2.29 & 25 & 32.7 \\
Peak 2 on Resource Q column & & 0.56 & 1.5 & 0.40 & 4.2 & 5.71 \\
\hline
\end{tabular}


Active eluted fractions from gel filtration and Resource $Q$ were then loaded onto denaturing gel electrophoresis. As shown in Supplementary Fig. 3, ferredoxin-NAD+ reductase activity from gel filtration was associated with the presence of 3 proteins of 41, 37, and $34 \mathrm{kDa}$, and ferredoxin-NAD+ reductase activity from Resource $\mathrm{Q}$ was linked to the presence of two proteins of 167 and $53 \mathrm{kDa}$. All proteins were eluted, digested by trypsin and analyzed by nano-LC-MS/MS as described in Methods. The results indicated that the three proteins eluted from gel filtration were the three subunits of butyryl-CoA dehydrogenase encoded by $b c d$, etfB and etfA, and the two proteins eluted from ResourceQ were the two subunits of NADHdependent glutamate synthase encoded by $g / t A$ and $g / t B$. The BCD enzyme complex was previously shown to have NADH-ferredoxin reductase activity in the presence of crotonyl-CoA (19). This study shows clearly that BCD also has ferredoxin-NAD+ reductase activity in the absence of crotonyl-CoA or butyryl-CoA.

To determine if ferredoxin-NAD+ reductase activity could be obtained in the absence of $\mathrm{Bcd}$, the etfb-etfa genes were cloned on a replicative plasmid with a sequence encoding Strep-tag II placed in the $3^{\prime}$ position of etfB with and without bcd as the first gene of the synthetic operon, as described in Yoo et al. 2015. The recombinant proteins were produced in E. coli from the two plasmids and then purified on a Strep-Tactin column. When all three genes were expressed, an active complex could be purified, while when only two genes were expressed, only EtfB could be purified, indicating that EtfB and EtfA cannot form a complex in the absence of Bcd.

The ferredoxin-NAD ${ }^{+}$reductase, ferredoxin-NADP ${ }^{+}$reductase, $\mathrm{NADH}$-ferredoxin, and NADPHferredoxin reductase activities of the Bcd-EtfAB complex were evaluated in the purified active fraction recovered from C. acetobutylicum. According to Fig. 4, the purified complex exhibited 
ferredoxin-NAD ${ }^{+}$reductase activity, but no ferredoxin-NADP ${ }^{+}$reductase activity, no NADHferredoxin, and no NADPH-ferredoxin reductase activity were detected. These results confirmed that in addition to its butyryl-CoA dehydrogenase activity, the Bcd-EtfA-EtfB complex can exhibit ferredoxin-NAD+ reductase activity in the absence of any CoA derivative.

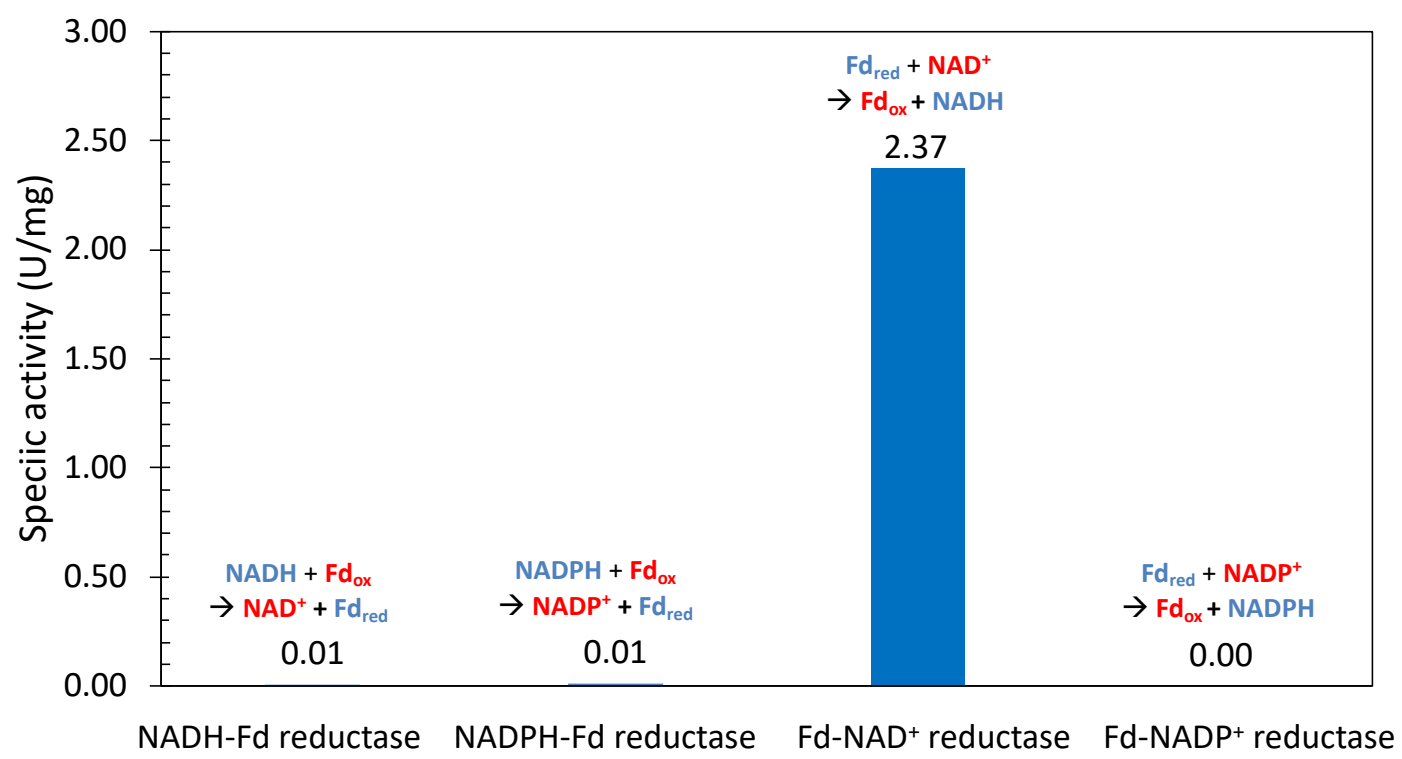

Fig. 4: Enzyme activities of the purified Bcd-EftB-Strep-tag-EtfA complex overexpressed and purified from $C$. acetobutylicum cells.

Finally, the ferredoxin-NAD ${ }^{+}$reductase, ferredoxin-NADP ${ }^{+}$reductase, NADH-ferredoxin reductase, and NADPH-ferredoxin reductase activities of the GltAB complex were evaluated in the purified active fraction recovered from $C$. acetobutylicum. Both ferredoxin-NAD+ reductase and $\mathrm{NADH}$-ferredoxin reductase activities were detected, while no ferredoxin$\mathrm{NADP}^{+}$reductase or NADPH-ferredoxin reductase activity was measured, indicating that GltAB is strictly NADH/NAD+ dependent.

\section{Construction of knockout mutants of the genes encoding enzymes with ferredoxin-NAD+} reductase and ferredoxin-NADP ${ }^{+}$reductase activities:

To investigate the role of ferredoxin- $\mathrm{NAD}(\mathrm{P})^{+}$reductases in the production of butanol in vivo, group II intron-based ClosTron technology (27) was used to inactivate the CA_CO764, gltB and 
etfB genes in MGCAcac1502 (28). This technology uses the insertion of a group II intron into a genomic target site coupled to a retrotransposition-activated marker (erythromycin resistance), allowing stable gene inactivation. The retargeted introns were first directed to be inserted at position 407/408 on the sense strand of $C A \_C 0764$ and at position 181/182 on the sense strand of $g / t B$. After mutagenesis, the insertion mutants were checked by combining PCR screening, sequencing and Southern hybridization (Fig. 4). Both MGCAcac1502CA_C0764-408s::CT and MGCAcac1502-gltb181s::CT were successfully constructed.

A

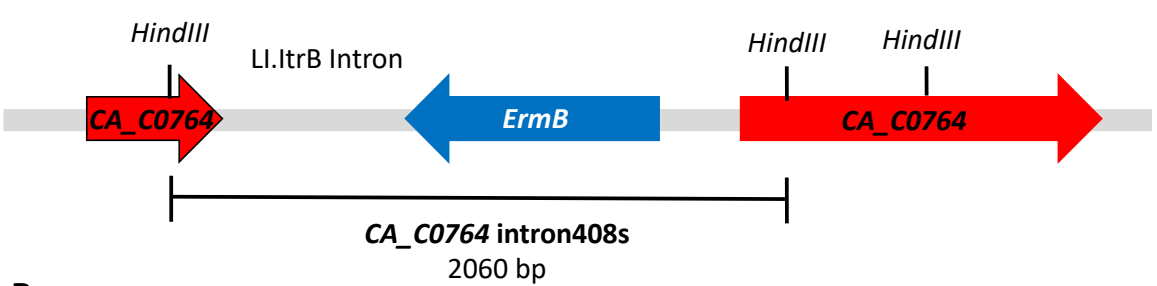

B

8 $\begin{array}{lll}1 & 2 & 3\end{array}$

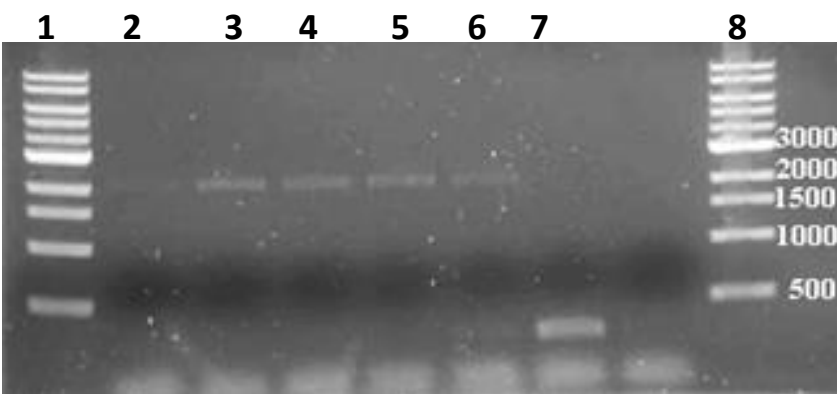

C

D $\begin{array}{llll}1 & 2 & 3 & 4\end{array}$

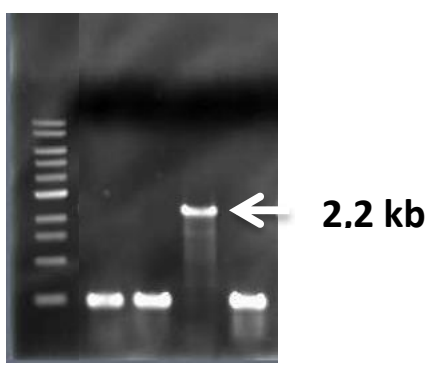

Fig 4: Construction of the MGCAcac1502-CA_C0764-408s::CT and MGCAcac1502-gltb181s::CT mutants: A) Schematic representation of the $C A \_C 0764$ gene with a group II intron inserted at position 408 on the sense strand of CA_C0764. B) PCR screening for the identification of putative CA_C0764408s::CT mutants using gene-specific primers flanking the intron insertion site (lanes 2 to 5 ) (expected size $2060 \mathrm{bp}$ ) and PCR control with wild-type DNA (lane 7) (expected size $270 \mathrm{bp}$ ), lanes 1 and 8 DNA 
ladder. C) Southern hybridization to demonstrate the presence of a single intron insertion in the selected MGCAcac1502cac0764-408s::CT mutant. The intron probe was DIG labeled and hybridized to HindIII-HF digested genomic DNA of the MGCAcac1502cac0764-408s::CT mutant (lane 2) with an expected size of $1970 \mathrm{bp}$. The HindIII-HF digested genomic DNA of the C. acetobutylicum MGCAcac1502 strain (lane 1) was also tested as a negative control. Lane 3 is a $1 \mathrm{~kb}$ DNA ladder. D) PCR screening for the identification of putative gltb181s::CT mutant using gene-specific primers flanking the intron insertion site (lanes 1 to 3) (expected size $2200 \mathrm{bp}$ ) and PCR control with wild-type DNA (lane 4) (expected size $500 \mathrm{bp}$ ), lane 1 DNA ladder.

A similar approach using the ClosTron method was used to inactivate the etfB gene. Despite repeated attempts and the use of at least two different retargeted ClosTron plasmids, insertions into the etfB gene could not be obtained. The low number of erythromycin-resistant clones that did arise had apparently inserted elsewhere in the genome, suggesting that the ferredoxin-NAD+ reductase activity of $\mathrm{BCD}$ is essential for $C$. acetobutylicum.

\section{Role of ferredoxin-NADP ${ }^{+}$reductase in the central metabolism of $C$. acetobutylicum:}

To better understand the role of ferredoxin-NADP ${ }^{+}$reductase in the central metabolism of $C$. acetobutylicum, the growth and product formation of a strain with an inactivated cac0764 gene (MGCAcac1502CA_C0764-408s::CT) and a strain overexpressing cac0764 (MGCAcac1502 (pCLFCA_C0764)) were compared to the control MGCAcac1502 strain and the MGCAcac1502 (pCons2-1) strain containing an empty control plasmid, respectively. The final product yields of all strains after 10 days of culture are shown in Fig. 5 A and B: 


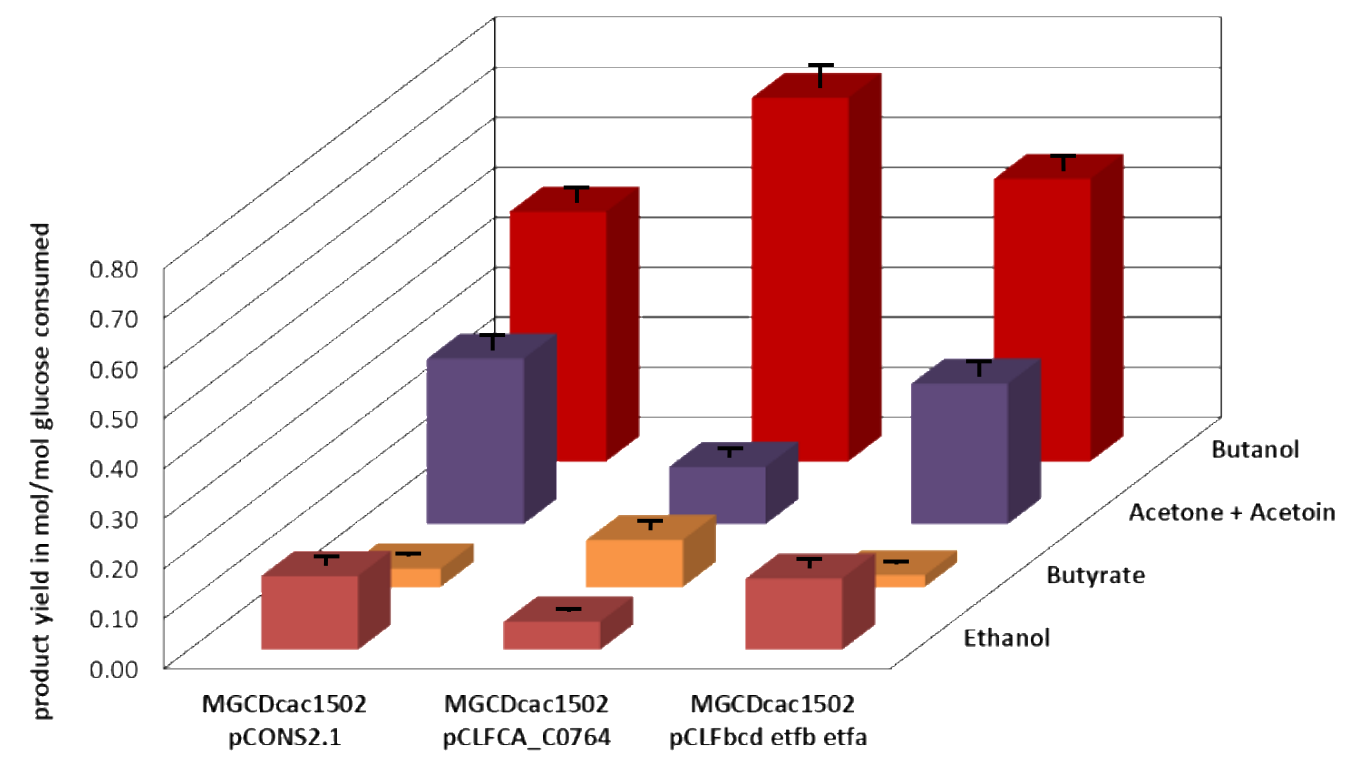

B

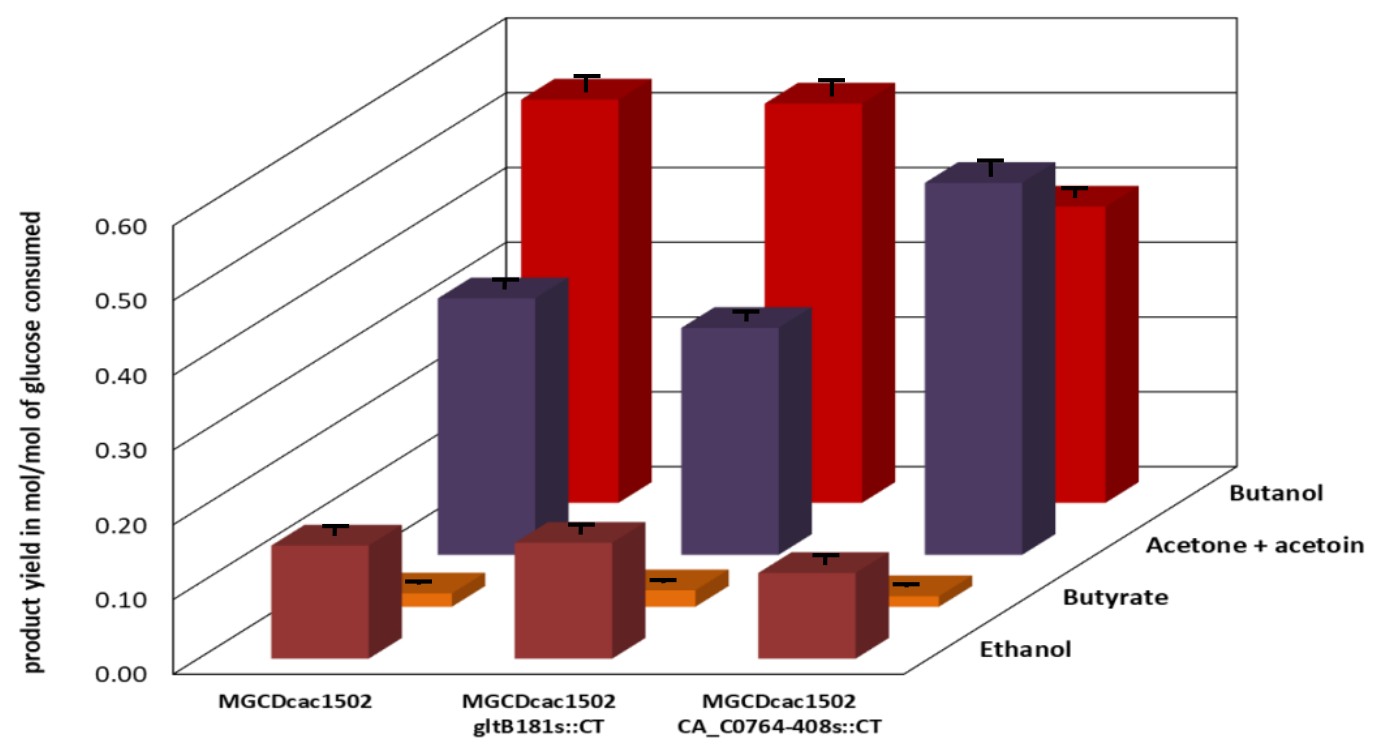

Fig. 5: Comparative final product yields in $\mathrm{mol} / \mathrm{mol}$ of glucose consumed for all $C$. acetobutylicum strains: A) MGCAcac1502 (pCons2-1), MGCAcac1502 (pCLFCA_C0764), MGCAcac1502 (pCLFbcd-etfb-etfa) B) MGCAcac1502, MGCAcac1502-gltB181s:CT, MGCAcac1502-CA_C0764-408s::CT. Each error bar indicates the SEM around the mean of three independent cultures.

Fig. 5B shows that the inactivation of the gene encoding the ferredoxin-NADP ${ }^{+}$reductase caused a marked decrease in the butanol yield ( $40 \%$ of the theoretical yield) in comparison to the parental MGCAcac1502 strain (54\% of the theoretical yield). Conversely, the acetone + 
acetoin yield was almost doubled (34\% of the theoretical yield in the parental MGC $\triangle$ cac1502 strain versus $50 \%$ of the theoretical yield when CA_CO764 was inactivated). On the other hand, the overexpression of the ferredoxin-NADP ${ }^{+}$reductase-encoding gene (Fig. 5a) favored butanol production and significantly increased the butanol yield (from $50 \%$ to $72 \%$ of the theoretical yield) at the expense of acetone + acetoin production, whose yield was strongly reduced from $33 \%$ to $11 \%$ of the theoretical yield. Finally, the strain with the ferredoxin-NADP ${ }^{+}$ reductase-encoding gene inactivated could be complemented by the introduction of the pCLF0764 plasmid overexpressing CA_C0764, which restored high butanol production (68\% of the theoretical yield) (Supplementary Fig. 4). All these results were confirmed by ferredoxin$\mathrm{NADP}^{+}$reductase activity measurements (Fig. 6), which showed negligible ferredoxin-NADP ${ }^{+}$ reductase activity $(<0.001 \mathrm{U} / \mathrm{mg})$ when $C A \_0764$ was inactivated and high ferredoxin-NADP+ reductase specific activity when CA_0764 was overexpressed from the $p C L F 0764$ plasmid (1.54 $\mathrm{U} / \mathrm{mg}+/-0.07$, versus $0.0326 \mathrm{U} / \mathrm{mg}+/-0.007$ for the control).

These results clearly demonstrated the involvement of the ferredoxin-NADP ${ }^{+}$reductase enzyme in the butanol production pathway of $C$. acetobutylicum under solventogenic conditions. Moreover, it was also demonstrated that the yield of $n$-butanol was limited by the level of ferredoxin-NADP ${ }^{+}$reductase activity.

Role of each of the two enzymes with ferredoxin-NAD+ reductase activity in the central metabolism of $C$. acetobutylicum:

To better understand the role of ferredoxin-NAD+ reductases in the central metabolism of $C$. acetobutylicum, a strain with an inactivated gltB gene (MGCAcac1502-gltB181s:CT) and a strain overexpressing the genes encoding the Bcd-EtfB-EtfA complex (MGCAcac1502 (pCLF bcd-etfb-etfa)) were grown anaerobically in liquid flasks containing SM with $60 \mathrm{~g} / \mathrm{l}$ glucose 
under the same conditions, and the growth and product formation were measured. Comparative phenotypic analysis was performed by measuring both glucose consumption and the concentration of fermentation products. Inactivation of $g / t B$ had no effect on the product profile suggesting that the GltAB enzyme complex plays a minor role in the production of NADH from reduced ferredoxin. In contrast, overexpression of the bcd-etfb-etfa operon increased the butanol yield (from $50 \%$ to $56 \%$ of the theoretical yield) at the expense of acetone + acetoin production, which was reduced from $33 \%$ to $28 \%$ of the theoretical yield. This plus the fact that a knockout etfB mutant is not viable, strongly suggests that the $B C D$ complex is responsible for the ferredoxin-NAD reductase activity in C. acetobutylicum.

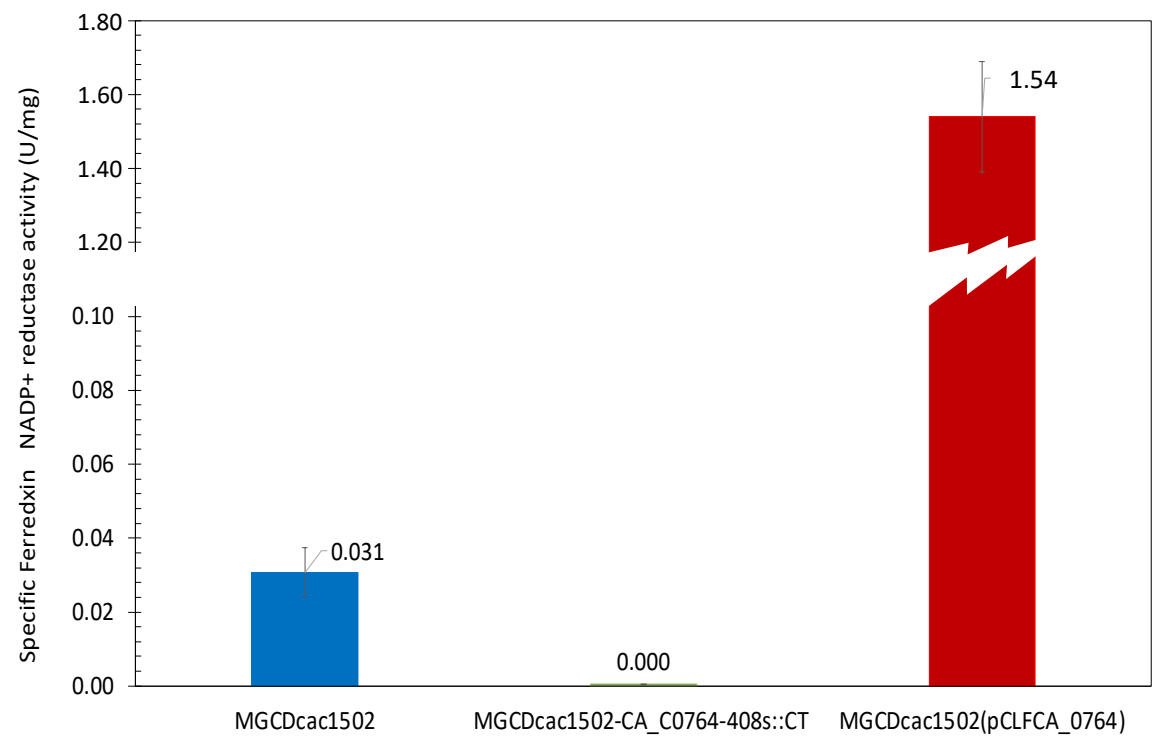

Fig. 6: Specific ferredoxin-NADP ${ }^{+}$reductase activity in the cell-free extracts of the MGCAcac1502 control strain and of both the MGCA1502-CA_C0764-408s::CT and MGCAcac1502(pCLFCA_0764) mutants. Values are averages from two biological duplicates.

\section{NADPH production in the MGCA1502-CA_C0764-408s::CT mutant:}

In this study, we showed that under solventogenic conditions, CAC0764 is the sole enzyme responsible for ferredoxin-NADP ${ }^{+}$reductase activity in C. acetobutylicum. As it was previously demonstrated that the oxidative pentose-phosphate pathway is missing in C. acetobutylicum $(21,26)$, we addressed the following question: how can the MGCAcac1502-CA_C0764- 
408s::CT mutant generate the NADPH needed for residual butanol production and anabolic reactions? Another NADPH-producing enzyme already identified in C. acetobutylicum is glyceraldehyde-3-phosphate dehydrogenase (GapN), encoded by CA_C3637, a nonphosphorylating enzyme that catalyzes the oxidation of glyceraldehyde-3-phosphate to 3phosphoglycerate (Fig. 1). In solventogenic chemostat cultures, this enzyme was shown to catalyze less than $5 \%$ of the total flux of the EMP pathway (19). To determine whether gapN could be upregulated in the MGCAcac1502-CA_C0764-408s::CT mutant in comparison to the MGCA1502 control strain, quantitative reverse-transcriptase PCR (RT-qPCR) analysis was carried out in both strains to determine the relative expression of the gap $N$ and gapC (encoding the NADH-dependent GAPDH) genes using the fabZ gene as the normalization reference gene (29). Experiments were performed as described in the Materials and Methods, and the normalized fold expression of both gapN and gapC in both the MGCAcac1502 and MGCAcac1502-CA_C0764-408s::CT strains is presented in Fig. 7.

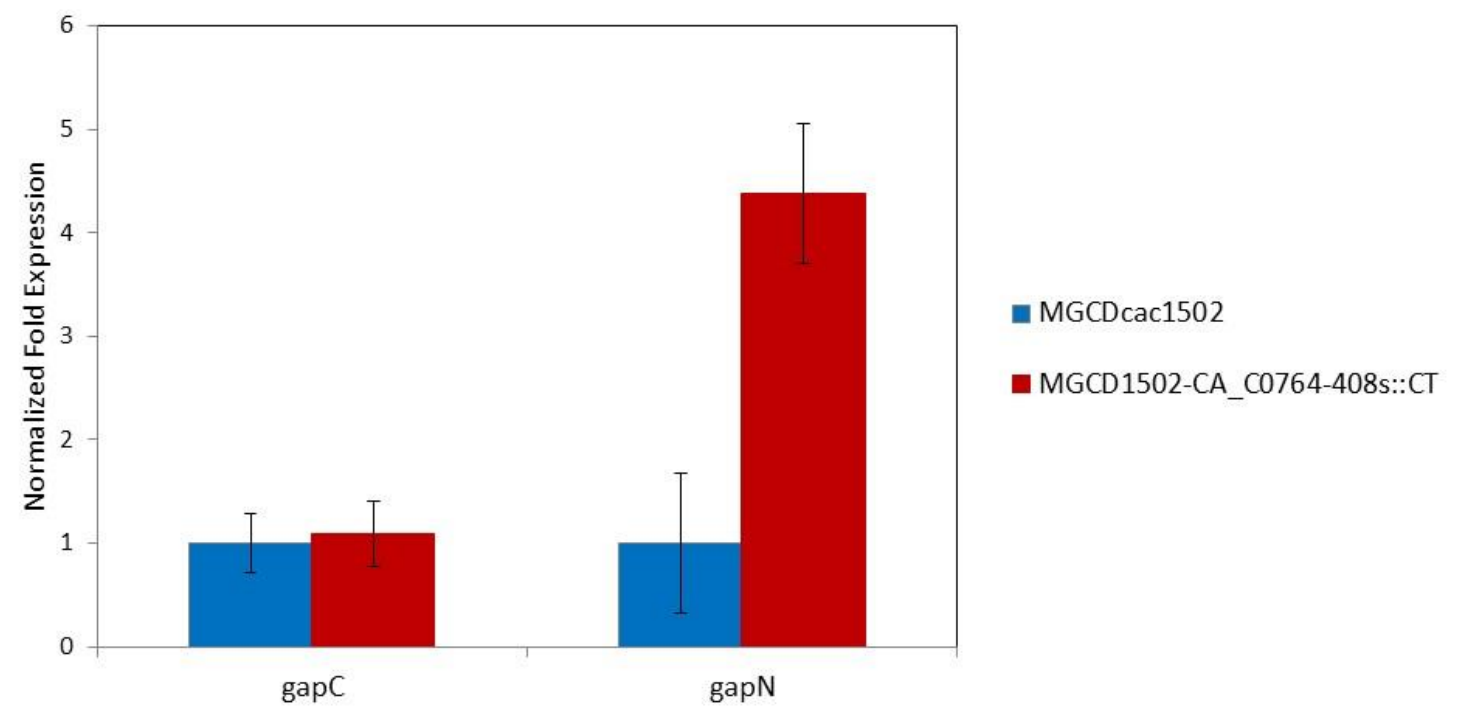

Fig. 7: Normalized fold expression of gapC and gapN genes in MGCAcac1502-CA_C0764-408s::CT (red). 
According to Fig. 7, the relative expression level of gapN in the MGCA1502-CA_C0764408s::CT mutant was 4.3-fold higher than the relative expression level of gapN in MGCAcac1502, showing that this gene was upregulated in the mutant strain.

Based on the phenotypic analysis performed under solventogenic conditions, the ferredoxin$\mathrm{NADP}^{+}$reductase activity determination in the cell crude extract, and the GapN expression results, a redox analysis was performed to determine how reduced ferredoxin is used to achieve the redox balance in each strain (Table 5).

\begin{tabular}{|c|c|c|c|}
\hline & \multicolumn{3}{|c|}{ STRAINS } \\
\hline & MGCA1502 & $\begin{array}{c}\text { MGCA1502CA-C0764- } \\
408 \mathrm{~s}:: C T\end{array}$ & $\begin{array}{c}\text { MGCA1502 } \\
\text { pCLFCac0764 }\end{array}$ \\
\hline moles of NADH produced in the glycolytic pathway & 2 & 1.44 & 2 \\
\hline moles of NADPH produced in the glycolytic pathway & 0 & 0.56 & 0 \\
\hline moles of NADH produced from reduced ferredoxin & 0.55 & 0.47 & 1.6 \\
\hline mole of NADPH produced from reduced ferredoxin & 0.74 & 0 & 0.8 \\
\hline mole of Fdred reoxidized by hydrogenase & 1.2 & 1.85 & 0.33 \\
\hline
\end{tabular}

As shown in Table 5, when CAC0764 is inactivated, reduced ferredoxin is mainly used for hydrogen production by HydA hydrogenase, a lower amount is used for NADH production (needed for ethanol, butyrate, lactate and butanol synthesis), and $28 \%$ of the EMP flux is catalyzed by GapN to produce the NADPH needed for $n$-butanol synthesis and anabolism. In contrast, when CAC0764 is overexpressed, reduced ferredoxin is mainly used for the NADH and NADPH formation needed for ethanol, butyrate and butanol production and anabolic reactions. 


\section{Discussion:}

Ferredoxin-NAD ${ }^{+}$and ferredoxin-NADP ${ }^{+}$reductase activities were measured in $C$. acetobutylicum more than 40 years ago (20). Their activities under different physiological conditions were further studied by other groups, but the proteins were never purified and characterized $(2,6)$. Their key role in butanol production was also suggested long ago from a stoichiometric model of the metabolism (30) but never demonstrated using a reverse genetic approach. More recently, using an updated genome-scale model constrained by transcriptomics and proteomics data, Yoo et al. in 2015 quantified and demonstrated for the first time the need for both ferredoxin-NAD ${ }^{+}$and ferredoxin-NADP ${ }^{+}$reductases to produce butanol under solventogenic conditions. As all the efforts to identify these proteins through blast searches were unsuccessful, a classical purification protocol was developed to isolate both the ferredoxin-NAD and ferredoxin-NADP ${ }^{+}$reductases of $C$. acetobutylicum. The applied strategy enabled the identification of only one protein catalyzing ferredoxin-NADP ${ }^{+}$reductase activity (encoded by the CA_CO764 gene) and two enzyme complexes (Bcd-EtfA-EtfB and GltAB) having a ferredoxin-NAD+ reductase activity.

The ferredoxin-NADP ${ }^{+}$reductase from $C$. acetobutylicum does not share any amino acid identity with previously described ferredoxin-NADP ${ }^{+}$reductases from other bacteria and shares $30 \%$ identity with GltB (the $\beta$ chain of NADH-dependent glutamate synthase), explaining its incorrect annotation. However, it is expressed as a monocistronic operon, which does not fit with a genetic organization as a bicistronic operon of glutamate synthaseencoding genes. CAC0764 was demonstrated to be strictly NADPH/NADP ${ }^{+}$dependent, and FAD is required to retain full enzyme activity, as is generally described for the ferredoxin$\mathrm{NADP}^{+}$reductase enzyme family (22). 
The two enzyme complexes with $\mathrm{NADH}$-ferredoxin reductase activity $\mathrm{BCD}$ and GItAB were previously shown to be a butyryl-CoA dehydrogenase (19), and an NADH dependent glutamate synthase (19) respectively. As the inactivation of gltB had no effect on the product profile, the GItAB enzyme complex probably plays a minor role in vivo in electrons transfer from reduced ferredoxin to $\mathrm{NAD}^{+}$. In contrast, the fact that i) overexpression of the bcd-etfbetfa operon increased the butanol yield and ii) a knockout etfB mutant is not viable, strongly suggests that the BCD complex is responsible for the ferredoxin-NAD+ reductase activity in $C$. acetobutylicum. $\mathrm{BCD}$ is a bifurcating enzyme reducing crotonyl-CoA to butyryl-CoA with the consumption of two NADHs and the production of one reduced ferredoxin. This allows the endergonic transfer of electrons from NADH to oxidize ferredoxin and eliminate the excess NADH associated with acetate production in acidogenic conditions $(6,19)$. What is new here is that in the absence of crotonyl-CoA or butyryl-CoA, this enzyme can also carry exergonic electrons transfer from reduced ferredoxin to $N A D^{+}$.

From a physiological perspective, inactivation of the ferredoxin-NADP+-encoding gene significantly decreased butanol production and increased acetone production, while its overexpression had the opposite effect, with a very high n-butanol yield from glucose of $72 \%$ of the theoretical value. This suggests that butanol production, under solventogenic conditions, is potentially limited by the flux of NADPH production and demonstrates that the carbon fluxes can also be modulated by manipulating the electron fluxes. Furthermore, in the absence of ferredoxin-NADP ${ }^{+}$reductase, $C$. acetobutylicum maintains a certain flux of NADPH production by expressing a higher level of gapN, a gene coding for nonphosphorylating NADP ${ }^{+}$ dependent glyceraldehyde-3-P dehydrogenase. In this mutant, up to $28 \%$ of the EMP flux is catalyzed by GapN, resulting in lower ATP production. 
Attempts to knock out etfB to abolish ferredoxin-NAD+ reductase activity have been unsuccessful. This suggests that $C$. acetobutylicum cannot grow in the absence of ferredoxin$\mathrm{NAD}^{+}$reductase activity. Consistently, all the electron flux analyses performed on chemostat cultures of $C$. acetobutylicum in acidogenic, solventogenic or alcohologenic conditions (19) show a high flux in the reaction catalyzed by ferredoxin-NAD+ reductase. Furthermore, we can demonstrate using the 965 genome-scale model that an etfB mutant that would be unable to produce butyrate and butanol and would have no ferredoxin-NAD+ reductase activity could survive only if it produced lactate as the only fermentation product. Such a drastic redirection of the metabolic fluxes is probably not possible by regulation of the metabolic pathway and might explain why the etfB mutant is not viable.

The discovery of the ferredoxin-NADP ${ }^{+}$and ferredoxin-NAD ${ }^{+}$reductase-encoding genes and the demonstration of their key role in butanol production present the possibility of new metabolic engineering strategies to create a homobutanologenic $C$. acetobutylicum strain.

\section{Conclusion:}

To the best of our knowledge, these results are the first to be reported on the purification, identification and characterization of the ferredoxin-NADP ${ }^{+}$reductase and ferredoxin-NAD reductase of $C$. acetobutylicum. The involvement of the identified enzymes in butanol synthesis under solventogenic conditions was shown.

\section{Methods:}

Bacterial strains, plasmids and oligonucleotides:

All bacterial strains, plasmids and oligonucleotides used in or derived from this study are listed in Supplementary Tables 1 and 2. 


\section{Culture media and growth conditions:}

E. coli strains were grown aerobically at $37^{\circ} \mathrm{C}$ in Luria-Bertani (LB) medium supplemented, when necessary, with ampicillin $(100 \mu \mathrm{g} / \mathrm{mL})$ and/or chloramphenicol (30 $\mu \mathrm{g} / \mathrm{mL})$. Agar (15 g/L) was added prior to sterilization on LB agar plates.

MGCAcac1502, MGCAcac1502-CA_C0764-408s::CT, and MGCAcac1502 gltB181s::CT strains were kept in spore form at $-20^{\circ} \mathrm{C}$ in synthetic medium (SM). MGCA1502-CA_C0764-408s::CT pCLFCA_C0764, MGCA1502 pCLFCA_C0764, MGCA1502 pCLF bcd-etfb-etfa and MGCA1502 pCons2-1 strains were kept on glucose SM plates with thiamphenicol $(10 \mu \mathrm{g} / \mathrm{mL})$ and directly used to inoculate liquid flask cultures containing glucose SM with thiamphenicol $(50 \mu \mathrm{g} / \mathrm{mL})$. The liquid flask cultures of all C. acetobutylicum strains were grown anaerobically at $37^{\circ} \mathrm{C}$ in $30 \mathrm{~mL}$ of SM as previously described (7) with $60 \mathrm{~g} / \mathrm{L}$ glucose.

\section{Analytical procedures:}

The cell concentration was measured turbidimetrically by monitoring the optical density (OD) at $620 \mathrm{~nm}$; an experimentally derived correlation factor of $0.3 \mathrm{~g}$ cellular dry weight per $\mathrm{OD}_{620}$ $\mathrm{nm}$ was used for the biomass concentration calculations. Glucose, pyruvate, lactate, acetate, butyrate, acetoin, glycerol, ethanol, acetone and butanol concentrations were measured in the culture supernatants using high-performance liquid chromatography (HPLC) analysis (Agilent 1200 series, Massy, France) as previously described (17).

\section{Enzyme assays:}

\section{Ferredoxin-NAD(P)+ reductase activity and NADPH-ferredoxin reductase activity assays:}

All enzyme assays were performed in an anaerobic workstation under a nitrogen atmosphere. All reagent solutions were prepared in assay buffer (previously boiled and degassed with nitrogen) and kept under a nitrogen atmosphere. Specific activities were determined in a range where linearity with protein concentration was established. Each enzyme assay was 
done at least in duplicate. One unit of enzyme activity is defined as the amount of enzyme that catalyzes the conversion of $1 \mu \mathrm{mol}$ of substrate per min. The concentrations of components in the reaction mixtures ( $1 \mathrm{~mL}$ of total volume) are given below.

In vitro ferredoxin-NAD(P)+ reductase activity was assayed by measuring the reduction of $\mathrm{NAD}^{+}$or $\mathrm{NADP}^{+}$using electrons from reduced ferredoxin (CA_CO303) with $\mathrm{H}_{2}$ as the reductant of ferredoxin (CA_CO303) (31) in the presence of Fe-Fe hydrogenase from Clostridium acetobutylicum (CA_CO028) (32). Ferredoxin (CA_C0303) was purified in the laboratory as previously described (32). The reaction was performed anaerobically at $37^{\circ} \mathrm{C}$ in $100 \mathrm{mM}$ Tris$\mathrm{HCl}$ buffer ( $\mathrm{pH}$ 7) with $2 \mathrm{mM}$ DTT, $25 \mu \mathrm{M}$ FAD, $13 \mu \mathrm{M}$ ferredoxin or $150 \mu \mathrm{M}$ methyl viologen, 1,6 $\mathrm{mM} \mathrm{NAD}^{+}$or $\mathrm{NADP}^{+}, 6 \mathrm{U}$ (or more) of purified hydrogenase HydA from C. acetobutylicum and crude extract (or purified protein), followed by monitoring the increase in $A_{340 \mathrm{~nm}}$ as an indication of the appearance of NADH or NADPH using a spectrophotometer (Hewlett Packard 8453). After a gentle stream with hydrogen in the quartz cuvette cells, assays were initiated by the addition of ferredoxin and then, after the reduction of ferredoxin (approximately 5 min), by the addition of $\mathrm{NAD}^{+}$or $\mathrm{NADP}^{+}$. In all reactions, nonenzymatic rates were subtracted from the observed initial reaction rates.

In vitro NADPH-ferredoxin reductase activity was assayed by monitoring the increase in $A_{560}$ $\mathrm{nm}$ as an indication of the reduction of methyl viologen using a spectrophotometer (Hewlett Packard 8453). The reaction was carried out anaerobically at $37^{\circ} \mathrm{C}$ in quartz cuvette cells in $100 \mathrm{mM}$ Tris-HCl buffer (pH 7,6) with $2 \mathrm{mM}$ DTT, $10 \mu \mathrm{M}$ FAD, $250 \mu \mathrm{M}$ NADPH, ethanol 3\% $\mathrm{vol} / \mathrm{vol}, 45 \mathrm{U}$ Adh (S. cerevisiae), $10 \mathrm{mM}$ methyl viologen, and crude extract or purified protein. Assays were initiated by the addition of methyl viologen. In all reactions, nonenzymatic rates were subtracted from the observed initial reaction rates. 
The extinction coefficients of methyl viologen at $560 \mathrm{~nm}$ and of NADH and NADPH at $340 \mathrm{~nm}$ were $7.71 \mathrm{mM}^{-1} \mathrm{~cm}^{-1}, 6.22 \mathrm{mM}^{-1} \mathrm{~cm}^{-1}$ and $6.29 \mathrm{mM}^{-1} \mathrm{~cm}^{-1}$, respectively. The total protein concentration of the cell-free extract or purified fraction was determined using the Bradford method (Bio-Rad reagent) (33) with bovine serum albumin as the standard.

\section{Purification of the ferredoxin-NAD ${ }^{+}$and ferredoxin-NADP ${ }^{+}$reductases in $C$. acetobutylicum} under solventogenic conditions:

The $C$. acetobutylicum ATCC 824 strain was kept in spore form at $-20^{\circ} \mathrm{C}$ in SM. The flask cultures of $C$. acetobutylicum strains were grown anaerobically in SM, inoculated with a spore stock at $10 \%(\mathrm{v} / \mathrm{v})$, and heat-shocked at $80^{\circ} \mathrm{C}$ for $15 \mathrm{~min}$. Cells were grown at $37^{\circ} \mathrm{C}$ to an $\mathrm{OD}_{620 \mathrm{~nm}}$ of approximately 2.0 , and the $\mathrm{pH}$ was maintained by buffering the culture medium with calcium carbonate prior to inoculation of the bioreactor at $10 \%(\mathrm{v} / \mathrm{v}) . \mathrm{pH}$-controlled batch fermentations were performed in SM. A 2 L Biostat B bioreactor (Sartorius, Aubagne, France) was used with a working volume of $1.3 \mathrm{~L}$ (34). After sterilization, the medium was sparged with $\mathrm{O}_{2}$-free nitrogen for $30 \mathrm{~min}$. During the course of the experiment, the medium was maintained under a slight nitrogen overpressure to avoid $\mathrm{O}_{2}$ entry into the reactor. All tubing was made of butyl rubber, and the reactor gas outlet was protected with a pyrogallol arrangement. Cultures were stirred at $300 \mathrm{rpm}$, the temperature was set at $35^{\circ} \mathrm{C}$, and the $\mathrm{pH}$ was maintained at 4.8 with the automatic addition of $\mathrm{NH}_{4} \mathrm{OH}(3 \mathrm{~N})$. The cell concentration was measured turbidimetrically by monitoring the optical density (OD) at $620 \mathrm{~nm}$ (Biochrom libra S11), and product formation was measured in duplicate using HPLC analysis (Agilent 1200 series, Massy, France) (17). When the $\mathrm{OD}_{620 \mathrm{~nm}}$ reached approximately 16, after the switch from the acidogenic to solventogenic phase, cells were harvested under hydrogen pressure and transferred into an anaerobic chamber. The cells were washed and concentrated 20 times in $100 \mathrm{mM}$ Tris- $\mathrm{HCl} 2 \mathrm{mM}$ DTT $10 \%$ glycerol $(\mathrm{pH} 7.6)$ buffer and frozen at $-80^{\circ} \mathrm{C}$. 
All purification procedures were performed under anaerobic conditions. All purification buffers were degassed in advance, and $10 \mu \mathrm{M}$ FAD and $2 \mathrm{mM}$ DTT were added to prevent nonreversible activity losses.

Frozen cells from solventogenic batch cultures of C. acetobutylicum ATCC 824 were thawed and broken by sonication using an ultrasonic disintegrator (Vibracell 72434 , Bioblock) at $4^{\circ} \mathrm{C}$ in four cycles of $30 \mathrm{~s}$ at 2-min intervals. Debris was removed by centrifugation at $8600 \times \mathrm{g}$ for 10 min at $4^{\circ} \mathrm{C}$ (Sigma centrifuge $2-16 \mathrm{~K}$ ). Nucleic acids were precipitated by the addition of streptomycin sulfate $(200 \mu \mathrm{g} / \mathrm{mL})$ to the supernatant and removed by centrifugation as described above. The recovered extract was then diluted 5 times in $100 \mathrm{mM}$ Tris- $\mathrm{HCl}$ buffer ( $\mathrm{pH}$ 8) before loading on a $5 \mathrm{~mL}$ HiTrap Capto DEAE matrix (GE Healthcare, ref. 28-9165-40) connected to an AKTA purifier (GE Healthcare, Sweden). Active fractions were screened with the ferredoxin $\mathrm{NAD}^{+}$and ferredoxin $\mathrm{NADP}^{+}$reductase assay using ferredoxin as previously described. The column was equilibrated in $100 \mathrm{mM}$ Tris- $\mathrm{HCl}$ buffer ( $\mathrm{pH}$ 8), and elution was performed with a 3-step gradient of $100 \mathrm{mM}$ Tris- $\mathrm{HCl}+1 \mathrm{M} \mathrm{NaCl}$ buffer $(\mathrm{pH}$ 8): $1 \mathrm{CV} 0-4 \%, 20$ CV 4-16\% (target elution) and 5 CV 16-100\%; $2 \mathrm{~mL}$ fractions were collected. For ferredoxin$\mathrm{NADP}^{+}$reductase activity, the most active fractions from the Capto DEAE column were pooled before being loaded on a Resource Q column equilibrated in $100 \mathrm{mM}$ Tris-HCl buffer ( $\mathrm{pH} 8$ ) for a second chromatographic step. The most active eluted fractions were then collected and concentrated on a Vivaspin 15/10000 MW (Sartorius Stedim, ref. VS1502) to reduce the sample volume to $150 \mu \mathrm{L}$ by centrifugation at $3000 \times \mathrm{g}$ for $15 \mathrm{~min}$. For the last purification step, a $150 \mu \mathrm{L}$ sample volume was loaded on a Superose $12,10 / 300 \mathrm{GL}$ column (GE Healthcare, ref. 17-5173-01) previously equilibrated in $100 \mathrm{mM}$ Tris- $\mathrm{HCl}+150 \mathrm{mM} \mathrm{NaCl}$ buffer (pH 7.6), and $400 \mu \mathrm{L}$ fractions were collected. For ferredoxin-NAD+ reductase activity, the active fractions from the Capto-DEAE column from each eluted peak were pooled before being loaded onto a 
Resource $\mathrm{Q}$ equilibrated in $100 \mathrm{mM}$ Tris- $\mathrm{HCl}$ buffer $(\mathrm{pH}$ 8) for a second chromatographic step or onto a Superose 12 10/300 GL column (GE Healthcare, ref. 17-5173-01) previously equilibrated in $100 \mathrm{mM}$ Tris- $\mathrm{HCl}+150 \mathrm{mM} \mathrm{NaCl}$ buffer $(\mathrm{pH} 7.6)$, and $400 \mu \mathrm{L}$ fractions were collected. Finally, the total protein concentration of the cell-free extract or purified fractions was determined using the Bradford method (Bio-Rad reagent) (31) with bovine serum albumin as the standard.

The yields and purification factor of each step were calculated. The purity factor of the separate active fractions was also evaluated using SDS electrophoresis in $40 \mathrm{~mL}$ polyacrylamide gels.

Identification of the gene coding for ferredoxin-NAD ${ }^{+}$and ferredoxin-NADP ${ }^{+}$reductase activities:

Active eluted fractions collected after Superose 12 or Resource $Q$ chromatography were loaded onto denaturing gel electrophoresis, and proteins were silver stained. For the ferredoxin-NADP ${ }^{+}$reductase active fraction, the region of the gel corresponding to the protein at $45 \mathrm{kDa}$ was used, and for the ferredoxin-NAD+ reductase active fractions, the regions of the gel corresponding to the proteins at i) 41,37 , and $34 \mathrm{kDa}$ and ii) at 167 and $53 \mathrm{KDa}$ were used. The gel regions were cut out using a sterile pipette tip. The gel plugs were then used for the identification of proteins by mass spectrometry. Each sample was subjected to trypsin digestion and analyzed by nano-LC-MS/MS on a CapLC-Q-TOF2 (Waters) and by MALDI on a MALDI MX (Waters). The candidate proteins were identified with ProteinLynx Global Server (Waters) and Mascot (Matrix Science) software using the Protein Data Bank entry for $C$. acetobutylicum. In both analyses, for ferredoxin-NADP ${ }^{+}$reductase activity, only one protein was identified with a significant score (77\% sequence coverage). For ferredoxin $\mathrm{NAD}^{+}$ 
reductase activity, four proteins were identified with significant scores: a) butyryl-CoA dehydrogenase, $58.6 \%$ sequence coverage; b) EtfB, $78.4 \%$ sequence coverage; c) GltA, $78.4 \%$ sequence coverage, and d) GltB, $50.7 \%$ sequence coverage.

\section{Purification of CAC0764 and Bcd-EtfB-EtfA fused with a Strep-tag:}

CAC0764 protein and Bcd-EtfB-CST-EtfA complex protein were produced and purified in the form of Strep-tag II fused proteins as described previously by Gauquelin et al. 2018 (30), with the following modifications: sodium dithionite was not added to the elution buffer, and $25 \mu \mathrm{M}$ FAD was added to all buffers. 


\section{References:}

1. Jones D T. Applied acetone-butanol fermentation, p 125-168. In Bahl H, Dürre P (ed), Clostridia: biotechnology and medical applications. Wiley-VCH Verlag $\mathrm{GmbH}$, Weinheim, Germany (2001).

2. Jones D.T. \& Woods D.R. Acetone-butanol fermentation revisited. Microbiol Res 50:484524 (1986).

3. Jones DT, Van der Westhuizen A, Long S, Allcock ER, Reid SJ, \& Woods DR. Solvent production and morphological changes in Clostridium acetobutylicum. Appl Environ Microbiol 43:1434-1439 (1982).

4. Durre P. Biobutanol: an attractive biofuel. Biotechnol. J. 2, 1525-1534 (2007).

5. Ni Y, \& Sun Z. Recent progress on industrial fermentative production of acetone-butanolethanol by Clostridium acetobutylicum in China. Appl Microbiol Biotechnol 83:415-423. http://dx.doi.org/10.1007/s00253-009-2003-y (2009)

6. Vasconcelos I, Girbal L, \& Soucaille P. Regulation of carbon and electron flow in Clostridium acetobutylicum grown in chemostat culture at neutral $\mathrm{pH}$ on mixtures of glucose and glycerol. J Bacteriol 176: 1443-1450 (1994).

7. Girbal L, \& Soucaille P. Regulation of Clostridium acetobutylicum metabolism as revealed by mixed-substrate steady-state continuous cultures: role of NADH/NAD ratio and ATP pool. $J$ Bacteriol 176: 6433-6438 (1994).

8. Girbal L, Vasconcelos I, Saint-Amans S, \& Soucaille P. How neutral red modified carbon and electron flow in Clostridium acetobutylicum grown in chemostat culture at neutral pH. FEMS Microbiol Rev 16:151-162. http://dx.doi.org/10.1111/j.1574-6976.1995.tb00163.x (1995).

9. Girbal L, Croux C, Vasconcelos I, \& Soucaille P. Regulation of metabolic shifts in Clostridium acetobutylicum ATCC 824. FEMS Microbiol Rev 17 :287-297. http://dx.doi.org/10. 1111/j.1574-6976.1995.tb00212.x (1995).

10. Girbal L, \& Soucaille P. Regulation of solvent production in Clostridium acetobutylicum. Trends Biotechnol 16:11-16. http://dx.doi.org/10.1016/S0167-7799(97)01141-4 (1998).

11. Wiesenborn DP, Rudolph FB, \& Papoutsakis ET. Phosphotransbutyrylase from Clostridium acetobutylicum ATCC 824 and its role in acidogenesis. Appl Environ Microbiol 55:317-322 (1989a).

12. Wiesenborn DP, Rudolph FB, \& Papoutsakis ET. Coenzyme A transferase from Clostridium acetobutylicum ATCC 824 and its role in the uptake of acids. Appl Environ Microbiol 55:323329 (1989b). 
13. Sauer U, \& Dürre P. Differential induction of genes related to solvent formation during the shift from acidogenesis to solventogenesis in continuous culture of Clostridium acetobutylicum. FEMS Microbiol Lett 125: 115-120. http://dx.doi.org/10.1111/j.15746968.1995.tb07344.x (1995).

14. Soni B.K., Soucaille P. \& Goma G. Continuous acetone butanol fermentation: a global approach for the improvement in solvent productivity. Appl. Microbiol. Biotechnol. 25, 317321 (1987).

15. Soni B.K., Soucaille P. \& Goma G. Continuous acetone-butanol fermentation: influence of vitamins on the metabolic activity of Clostridium acetobutylicum. Appl. Microbiol. Biotechnol. 27, 1-5 (1987).

16.Jang YS , J.Y. Lee, J. Lee, J.H. Park, J.A. Im, M.H. Eom, J. Lee, S.H. Lee, H. Song, J.H. Cho, Y,Seung do, \& S.Y. Lee, Enhanced butanol production obtained by reinforcing the direct butanol-forming route in Clostridium acetobutylicum. MBio. 3, e00314-12 (2012)

17. Dusséaux S, Croux C, Soucaille P, \& Meynial-Salles I.. Metabolic engineering of Clostridium acetobutylicum ATCC 824 for the high-yield production of a biofuel composed of an isopropanol/butanol/ethanol mixture. Metab. Eng., 18,1-8 (2013).

18. Nguyen N P T, Raynaud C., Meynial-Salles I. \& Soucaiille P. Reviving the weizmann process for commercial n-butanol production, Nature communications, 9, 3682 (2018).

19. Yoo M, Bestel-Corre G, Croux C, Riviere A, Meynial-Salles I, \& Soucaille P. A quantitative system-scale characterization of the metabolism of Clostridium acetobutylicum. MBio 2015;6(6):e01808-15 (2015)

20. Petitdemange H. Cherrier C; Raval G. \& Gayn R. Regulation of the NADH and NADPH ferredoxin oxidoreductase in Clostridia of the butyric group, Biochimica et Biophysica Acta, 421, 334-347 (1976).

21. Lee J. Yun H., Feist A., Palsson B. \& Lee S. Y. Genome-scale reconstruction and in silico analysis of the Clostridium acetobutylicum ATCC824 metabolic network. Appl Microbiol. Biotechnol. 80, 849-862 (2008).

22. Ceccarelli E. A., Arakaki A. K., Cortez N. \&Carrillo N.. Functional plasticity and catalytic efficiency in plant and bacterial ferredoxin- NADP $(\mathrm{H})$ reductases Biochem Biophys. Acta, 155165 (2004).

23. Muller V., Chowdhury N. P. \& Basen M. Electron bifurcation: a long-hidden energycoupling mechanism: Annu. Rev. Microbiol., 72, 331-353 (2018).

24. Liang J., Huang H., \& Wang S. Distribution, Evolution, Catalytic Mechanism and Physiological Functions of the Flavin-based electron-bifurcating NADH-dependent reduced ferredoxin:NADP+ oxidoreductase: Frontiers in Microbiology, 1-12 (2019). 
25. Lo J., Zheng T., Olson D. G., Ruppertsberer N., Tripathi S.A., Guss A.M. and Lynd L. R. Deletion of nfnAB in Thermoanaerobacterium saccharolyticum and its effect on metabolism: J. Bacteriol., 197, 2920-2929 (2015).

26. Crown S.B., Indurthi D.C., Ahn W.S., Choi J., Papoutsakis E.T., \& Antoniewicz M.R. Resolving the TCA cycle and pentose-phosphate pathway of Clostridium acetobutylicum ATCC 824: Isotopomer analysis, in vitro activities and expression analysis., Biotechnol. J., 6 300-305 (2011).

27. Heap JT, Pennington OJ, Cartman ST, Carter GP, \& Minton NP. The ClosTron: a universal gene knock-out system for the genus Clostridium. J Microbiol Methods. 70:452-64 (2007)

28.Croux C, Nguyen NPT, Lee J., Raynaud C. Saint Prix F., Gonzales Pajuelo M. , Meynial-Salles I. \& Soucaille P. Construction of a restriction-less, marker-less mutant useful for functional genomic and metabolic engineering of the biofuel producer Clostridium acetobutylicum. Biotechnol. Biofuels. 9, 23 (2016).

29. Jones S.W., Paredes C.J., Tracy B., Cheng N., Sillers R., Senger R.S., \& Papoutsakis E.T. The transcriptional program underlying the physiology of clostridial sporulation, Genome Biol. 9, R114 (2008)

30 Papoutsakis E. T. Equations and calculations for fermentations of butyric acid bacteria: Biotech Bioeng, 174-187 (1983)..

31. Demuez M., Cournac L., Guerrini O., Soucaille P., Girbal . Complete activity profile of Clostridium acetobutylicum [FeFe]-hydrogenase and kinetic parameters for endogenous redox partners, FEMS Microbiol. Lett. 275, 113-121 (2007)

32. Gauquelin C, Baffert C, Richaud P, Kamionka E, Etienne E, Guieysse D, Girbal L, Fourmond V, André I, Guigliarelli B, Léger C, Soucaille P, Meynial-Salles I. Roles of the F-domain in [FeFe] hydrogenase Biochim Biophys Acta. Bioenergetics, 1859:69-77 (2018)

33. Bradford M. A rapid and sensitive method fort the quantification of microgram quantities of protein utilizing the principle of protein-dye binding. Anal. Biochem.72, 248-254 (1976)

34. Meynial-Salles I.*, Gonzalez-Pajuelo M.*, Mendes P., Andrade J. C., Vasconcelos I. \& Soucaille P. Metabolic engineering of Clostridium acetobutylicum for the industrial production of 1.3 propanediol from glycerol: Metabolic Eng., 7, 329-336 (2005). * equivalent contribution.

\section{Acknowledgments:}

This work was financially supported by the Agence Nationale de la Recherche (Grants ANR acetoH2 PNRB 2006 ANR Bio6 BioE-001, Biobutafuel ANR 088 BioE-012-01, Cellutanol ANR 14 CE05-0019-02) and by the BIOCORE European Project (Grant no. FP7-241566). The authors 
thank AJE for English language editing of the document (certification code 3DBE-123F-E411E361-B16P).

\section{Author contributions:}

$\mathrm{CF}, \mathrm{AR}, \mathrm{MH}, \mathrm{SDR}, \mathrm{CP}, \mathrm{MP}$, and SD designed and performed the experiments. LG participated in the conception of this study. PS and IMS conceived this study, analyzed the data, discussed the results and wrote the manuscript.

Additional information:

Supplementary information accompanies this paper.

\section{Competing interests:}

A patent application has been filed related to this work. 


\section{Supporting information:}

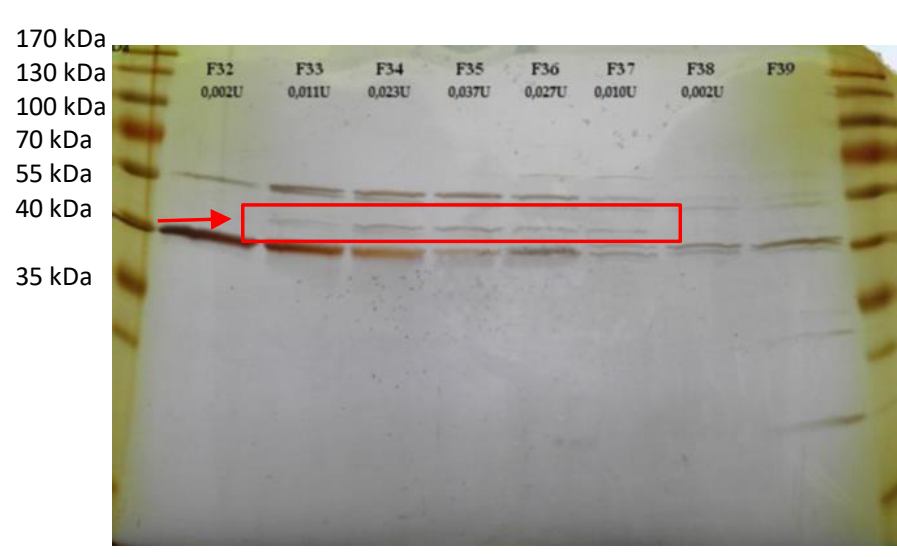

$\mathrm{MW} \sim 45 \mathrm{kDa}$

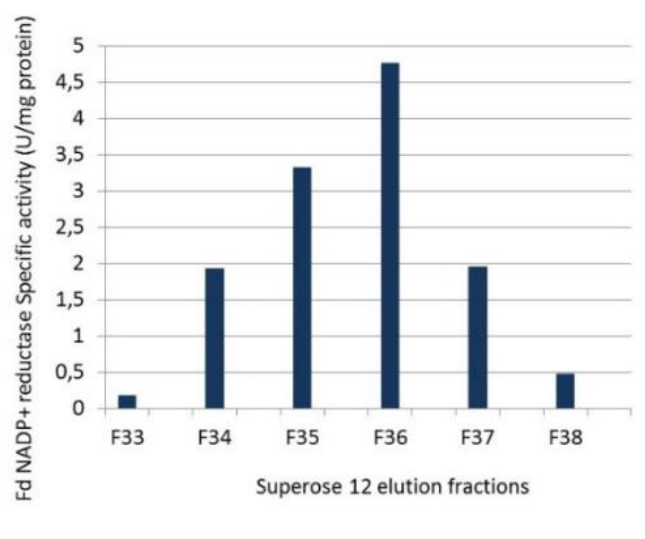

B

A Supplementary Fig. 1: a) SDS-PAGE analysis of active eluted fractions collected after Superose 12
chromatographic separation (proteins were silver stained). b) Ferredoxin-NADP ${ }^{+}$reductase activity of the corresponding fractions.

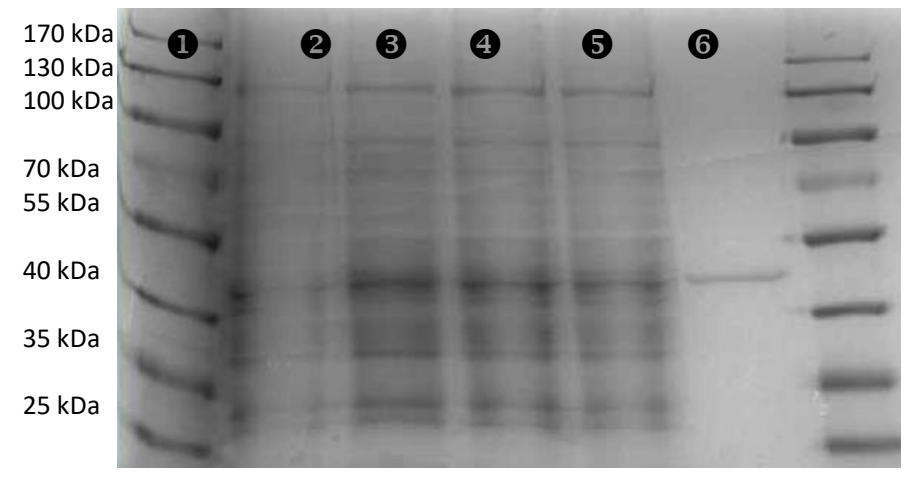

A

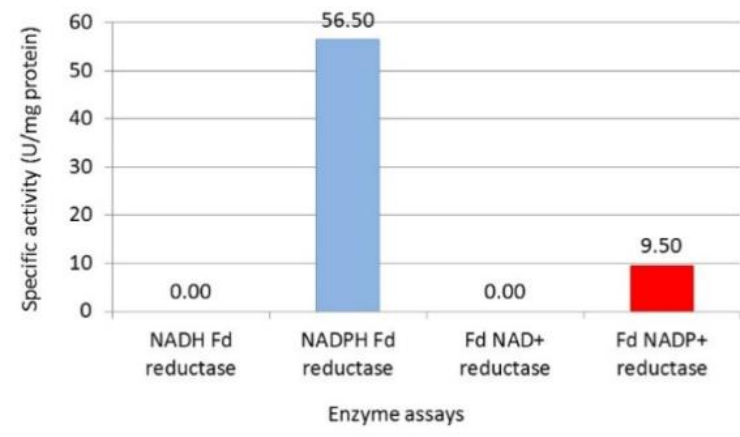

B

Supplementary Fig. 2: A) SDS-PAGE of purified CAC0764-Strep-tag 1) protein ladder 2) cell-free extract 3) streptomycin sulfate treatment 4) avidin treatment 5) loaded sample 6) active eluted fraction. B) Enzymatic activities of the CAC0764-Strep-tag protein determined using methyl viologen (blue) or reduced ferredoxin (red). 


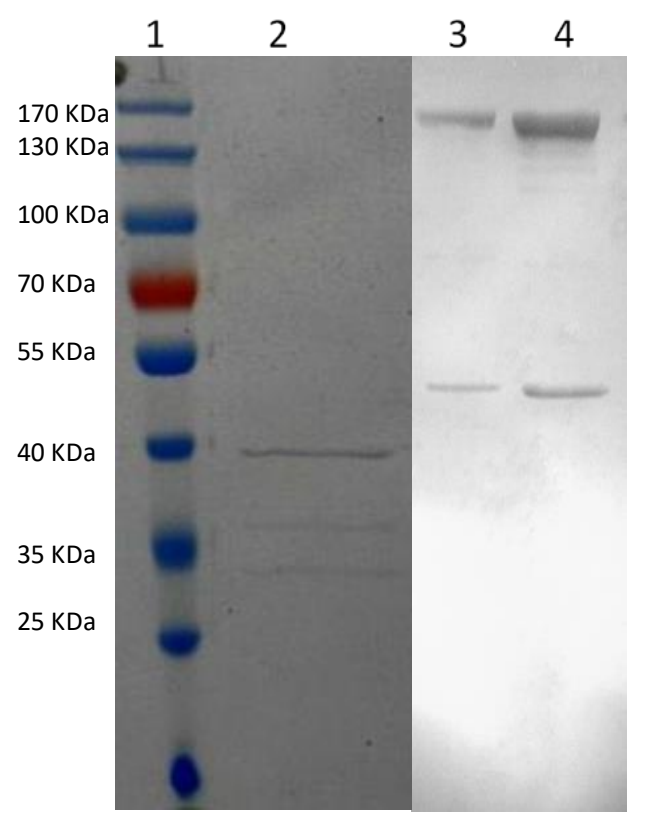

Supplementary Fig. 3: Silver-stained SDS-PAGE of the 1) protein ladder , 2) active eluted fractions from Resource $Q$, and 3-4) active eluted fraction from gel filtration.

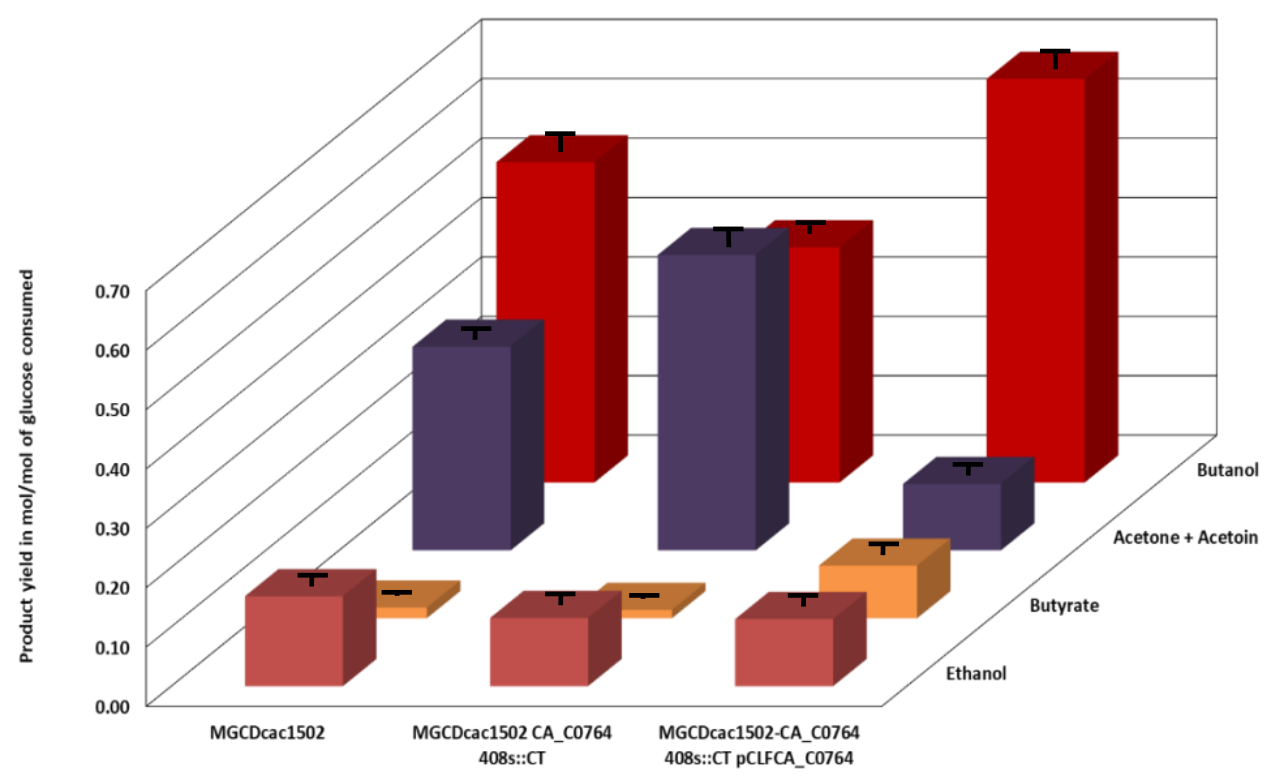

Supplementary Fig. 4: Comparative final product yields in $\mathrm{mol} / \mathrm{mol}$ of glucose consumed for the three C. acetobutylicum strains: MGCAcac1502, MGCAcac1502-CA_C0764-408s::CT, MGCAcac1502CA_C0764-408s::CT (pCLFCA_C0764). 


\begin{tabular}{|c|c|c|}
\hline \multicolumn{3}{|c|}{ Supplementary Table 1: List of strains and plasmids used in this study. } \\
\hline Strains/Plasmids & Relevant characterictics* & Source \\
\hline \multicolumn{3}{|l|}{ C. acetobutylicum } \\
\hline ATCC 824 & Wild type & ATCC \\
\hline MGC $\triangle 1502$ & $\Delta$ CA_C1502 & Croux et al. 2016 \\
\hline MGC $\Delta 1502$ pCons $2-1$ & $\Delta$ CA_C1502 & Croux et al. 2016 \\
\hline MGCA1502-CA_C0764-408s::CT & MGCA1502 CA_C0764 mutant & This study \\
\hline \multicolumn{3}{|l|}{ MGCA1502-CA_C0764-408s::CT } \\
\hline pCLFCA_C0764 & $\begin{array}{l}\text { complemented MGC } \triangle 1502 C A \_C 0764 \text { mutant } \\
\text { overexpression of } C A \_C 0467 \text { gene from the }\end{array}$ & This study \\
\hline MGC $\triangle 1502$ pCLFCA_C0764 & pCLF942 plasmid & This study \\
\hline MGC $\triangle 1502$-gltB181s::CT & $\begin{array}{l}\text { MGC } \triangle 1502 \mathrm{gltB} \text { mutant } \\
\text { overexpression of } b c d \text {-etfb-etfA genes from the }\end{array}$ & This study \\
\hline MGC $\triangle 1502 p C L F$ bcd-etfB-etfA & pCLF942 plasmid & This study \\
\hline \multicolumn{3}{|l|}{ E. coli } \\
\hline TOP10 & & Invitrogen \\
\hline \multicolumn{3}{|l|}{ Plasmids } \\
\hline pThl_HydA-LL-Ctag & $\mathrm{MLS}^{\mathrm{r}} ; \mathrm{AP}^{\mathrm{r}} ;$ repL; hydA & $\begin{array}{l}\text { Caserta et al. } \\
2018\end{array}$ \\
\hline pCST-LL-CA_C0764 & $\begin{array}{l}\text { with hydA promoter and adc terminator } \\
\text { pPH_HydA-LL-Ctag derivative with CA-CO764 } \\
\text { insertion and }\end{array}$ & This study \\
\hline pCST-LL-etfb-etfA & $\begin{array}{l}\text { pPH replacement with pthl } \\
\text { pPH_HydA-LL-Ctag derivative with etfb and etfa } \\
\text { insertion and }\end{array}$ & Yoo et al. 2015 \\
\hline & pPH replacement with pthl & \\
\hline pCST-LL-bcd-etfb-etfa & pCST-LL-etfBetfA derivative with bcd insertion & $\begin{array}{l}\text { Yoo et al. } 2015 \\
\text { GenBank: }\end{array}$ \\
\hline pSOS94 & $\begin{array}{l}\mathrm{MLS}^{\mathrm{r}} ; \mathrm{AP} \mathrm{P}^{\mathrm{r}} \text {, repL } ; \mathrm{ctfA} ; \mathrm{ctfB} ; \text { adc } \\
\text { with ptb promoter and adc terminator }\end{array}$ & AY187685.1 \\
\hline pCLF1 & $\mathrm{Cm}^{\mathrm{r}} ;$ repL $;$ flp 1 & Croux et al. 2016 \\
\hline pCLF CA_C0764 & $\begin{array}{l}\text { pCLF1 derivative with } C A \_C 0764 \\
\text { with } p t b \text { promoter and } a d c \text { terminator }\end{array}$ & This study \\
\hline pCLF bcd-etfb-etfa & $\begin{array}{l}\text { pCLF1 derivative with } b c d \text {-etfb-etfa } \\
\text { with } p t b \text { promoter and } a d c \text { terminator }\end{array}$ & This study \\
\hline pMTL007 & & Heap et al. 2007 \\
\hline pMTL007::cac-CA_C0764-408s & $\begin{array}{l}\text { ClosTron plasmid retargeted to } C \text {. acetobutylicum } \\
\text { CA_CO764 gene } \\
\text { ClosTron plasmid retargeted to } C \text {. acetobutylicum }\end{array}$ & This study \\
\hline pMTL007::cac-gltB181s & $\begin{array}{l}\text { gltB gene } \\
\text { ClosTron plasmid retargeted to } C \text {. acetobutylicum }\end{array}$ & This study \\
\hline pMTL007::cac-CA-C2710-159s & $\begin{array}{l}\text { CA_C2710 gene } \\
\text { ClosTron plasmid retargeted to C. acetobutylicum }\end{array}$ & This study \\
\hline pMTL007::cac-CA-C2710-101as & CA_C2710 gene & This study \\
\hline
\end{tabular}




\begin{tabular}{|ll|}
\hline \multicolumn{2}{|l|}{ Supplementary Table 2: List of primers used in this study. } \\
Name & Oligonucleotide sequences \\
\hline 408/409s-IBS & AAAAAAGCTTATAATTATCCTTAGGCTACAATGTTGTGCGCCCAGATAGGGTG \\
408/409s-EBS1d & CAGATTGTACAAATGTGGTGATAACAGATAAGTCAATGTTACTAACTTACCTTTCTTTGT \\
408/409s-EBS2 & TGAACGCAAGTTTCTAATTTCGATTTAGCCTCGATAGAGGAAAGTGTCT \\
cac0764del_for & cgagccaataaaatttcacgagata \\
cac0764del_rv & ccaacctctataagtctttcttcaagctta \\
Ocac0764f & AGGATCCATCAAAATTAGGAGGTTAGTTA \\
Ocac0764r & GGCGCCTTAATTATTCTTGCAATACTCATCAATAGTTTC \\
ESB universal & gtttactgaacgcaagtttctaatttcg \\
ErmB3'-R-F & cgccaaagtaaacaatttaagtaccgttac \\
fabZf & TCCAAGTATAGGCTTCTTTCCC \\
fabZr & GGTCATTACCCAGGTAAACCA \\
gapCf & CACATTAGATGGTCCACACAGAA \\
gapCr & AGCTAAGTCAGGAATAACTTGGC \\
gapNf & GGTTCTTGAGCTTGGTGGTAAA \\
gapNr & TTTACAGCAGTACACCTTTGGC \\
ccac0764BAMf & aattggatccatcaaaatttaggaggttagttagaatggataaccctaatttattgtcagaag \\
ccac0764SMAr & aattcccgggattattcttgcaatactcatcaatagtttc \\
CAC2710-101asIBS & aagcttataattatccttaccttccttatagtgcgcccagatagggtg \\
CAC2710-159sIBS & gcacttgaggaagtgcgcccagatagggtg \\
CAC2710-159sEBS1d & acaaagaaaggtaagttagcttcctcgacttatctgttatcaccacatttgtacaatctg \\
RBS nat bcd_rec for & AAATGAGCACGTTAATCATTTAACATAGATAATTGGATCCAGGAGGTAAGTTTATATGGATTT \\
etfa_rec_rev & AGAAACAATCTCTTTTACTGGCAAATCATTAAGTGGCGCCTTAATTATTAGCAGCTTTAACTTG \\
pCLF prom seq_for & AGCTATTAA \\
pCLF term_rev & AACACCACGTAGTTATTGGGAGG \\
psos prom univ & cttttggtcgtagagcacacgg \\
pSOSterm & ccgctcacaattccacacaacatacg \\
gltB_direct181S & GCTGCAGTTAATATGTAAGGGGGCGG \\
gltB_reverse181S & CCTTTGGAATCTTAGGCTTACCCCATCC \\
& \\
\hline
\end{tabular}

\section{Supplementary material:}

All of the chemicals were of reagent grade. Coenzymes such as methyl viologen, acetoacetylCoA, $\mathrm{NAD}(\mathrm{P}) \mathrm{H}$ and $\mathrm{NAD}\left(\mathrm{P}^{+}\right)$were purchased from Sigma Chimie (St. Quentin Fallavier, France). 
All gases used (carbon monoxide, nitrogen and a mixture of carbon monoxide, hydrogen and nitrogen) were of the highest purity available and were purchased from Air Liquid (Paris, France). DNA restriction enzymes, Antarctic phosphatase enzyme and T4 DNA ligase were obtained from New England Biolabs (Evry, France) and used according to the manufacturer's instructions. The proofreading Phusion DNA polymerase (New England Bioloabs) was used for PCR amplification prior to vector construction, and One taq DNA polymerase (New England Biolabs) was used for routine, control PCR amplifications. TOPO cloning was performed with the Zero Blunt TOPO Cloning Kit for sequencing as recommended by the manufacturer's instructions, and homologous cloning was performed with the GeneArt ${ }^{\circledR}$ Seamless Cloning \& Assembly Kit following the manufacturer's instructions (Thermo Fisher Scientific, Saint Aubin, France).

\section{Supplementary method 1: plasmid construction \\ 1-Construction of pMTL007::Cac-CA_C0764-408s:}

The intron target site was identified at bp 408/409 (from the start of the ORF) on the sense strand, and the intron retargeting PCR primers 408/409-IBS, 408/409-IEBS1d, and 408/409EBS2 (Supplementary Table 2) were designed using a computer algorithm (1). The three primer sets 408/409-IBS, 408/409-IEBS1d, 408/409-EBS2 and the EBS universal primers were used in a single-tube reaction with the pMTL007 plasmid (2) to mutate the intron at several positions spanning a $350 \mathrm{bp}$ region. PCR designed to retarget the intron by primer-mediated mutation was performed according to the protocol of the Targetron Gene Knockout System Kit (http://www.sigmaaldrich.com/life-science/functional-genomics-andrnai/targetron.html). The $350 \mathrm{bp}$ PCR fragment was purified and then cloned into the pMTL007 plasmid at the HindIII and BsrGI sites to replace the original intron fragment. The ligation product was then introduced into Top10 chemically competent $E$. coli cells 
(Invitrogen $\left.{ }^{T M}\right)$. Single colonies were then grown in LB liquid culture supplemented with ampicillin $(100 \mu \mathrm{g} / \mathrm{mL})$ overnight at $37^{\circ} \mathrm{C}$ to finally carry out DNA plasmid extraction (GenElute HP plasmid miniprep kit, Sigma) and check for the presence of the pMTL007::Cac-CA_0764408s plasmid. The retargeted pMTL007::Cac-CA_0764-408s plasmid was finally controlled by restriction and by DNA sequencing using the 408/409-IBS and 408/409-IEBS1d primers (Supplementary Table 2).

2-Construction of pMTL007Ca::gltB-180s: A similar method was applied to generate the intron-retargeted $p M T L 007 C a:: g / t B-180$ s plasmid. The intron target site was identified at $181 / 182 \mathrm{bp}$ on the sense strand using the Perutka algorithm (1).

3-Construction of pMTL007Cs::2710-101as and pMTL007Cs::2710-159s: As previously described, the Perutka algorithm (1) was used to identify the intron target site. Two positions, $101 / 102$ on the antisense strand and 159/160 on the sense strand, were selected.

\section{4-Construction of pCLF-CA_C0764:}

The CA_C0764 gene was amplified from the genomic DNA of C. acetobutylicum ATCC824 using the Ocac0764f and Ocac0764r primers (Supplementary Table 2). The primers were designed to introduce an RBS region along with the CA_CO764 gene, as well as placing BamHI and Sfol restriction sites upstream and downstream, respectively. The amplified PCR fragment was then subcloned into a Zero Blunt TOPO vector (Invitrogen, Saint Aubin, France) to yield the Zero Blunt TOPO-CA_CO764 plasmid, and the product was sequenced using universal primers T7P and T3P to assure that no mutations were introduced. The fragment containing the CA_CO764 gene was purified on an agarose gel after digestion of the Zero Blunt TOPOcac0764 vector with BamHI and Sfol. The $7 \mathrm{~kb}$ pSOS94 vector (3) was also digested with BamHI and Sfol and ligated to the BamHI-Sfol digested sadh gene, yielding the $6.25 \mathrm{~kb}$ pSOS94-CAC0764 vector. The pSOS94-CA_C0764 vector was digested with Sall, and the operon- 
containing fragments from each vector were purified on an agarose gel. The $4.9 \mathrm{~kb}$ pCLF1 vector (4) was digested with Sall, treated with Antarctic phosphatase and ligated with the previously purified fragment to yield pCLF-CA_CO764.

\section{5.-Construction of $p C L F-b c d$-etfb-etfa:}

The bcd-etfb-etfa operon was amplified from the genomic DNA of C. acetobutylicum MGCAcac1502 using the RBS nat bcd_rec_for and etfa_rec_rev primers (Supplementary Table 2). The primers were designed to introduce the native bcd RBS along with the operon and pCLF-CA_C0764 homologous regions. The purified PCR product was directly ligated with $p C L F-$ CA_C0764 previously digested with Scal et Sfol and purified using the GeneArt ${ }^{\circledR}$ Seamless Cloning \& Assembly Kit. The pCLF-bcd-etfb-etfa plasmid was controlled by PCR using the primers pCLF prom seq_for and pCLF term_rev (Supplementary Table 2), by restriction profiling, and finally by promoter-bcd-etfb-etfa-terminator region resequencing.

\section{6-Construction of the pCST-LL-CA_C0764:}

The CA_C0764 gene was amplified from the genomic DNA of C. acetobutylicum ATCC824 using ccac0764BAMf and ccac0764SMAr primers (Supplementary Table 2). The primers were designed to introduce an RBS region along with the CA_CO764 gene, as well as placing BamHI and Smal restriction sites upstream and downstream, respectively. The purified PCR product was further ligated with the product digested with BamHI and Smal and purified pthIACaHydA-LL-C-Tag plasmid (5), yielding the pCST-LL-CAC0764 vector. The pCST-LL-CAC0764 vector was checked by PCR using pSOSprom_univ and pSOSterm primers (Supplementary Table 2), by restriction profiling, and finally by promoter-CAC_O764-CST-terminator region resequencing. 


\section{Supplementary method 3: Transformation procedures:}

E. coli Top10 (Invitrogen) was transformed using heat shock $\left(30 \mathrm{~s}\right.$ at $42^{\circ} \mathrm{C}$ ) following the manufacturer's instructions.

MGC $\triangle \operatorname{cac} 1502$ was electroporated as previously described (6), except that unmethylated DNA was used because the cac1502 gene encoding the type II restriction endonuclease Cac824I was deleted (4). For transformation with the retargeted pMTL007::Cac-CA_C0764-408s, after 5 hours of recovery, cells were plated on RCA (Clostridium Nutrient Medium with $15 \mathrm{~g} / \mathrm{L}$ agar and Fluka (Saint-Quentin Fallavier, France, $\mathrm{n}^{\circ}$ 27546) medium supplemented with thiamphenicol $(10 \mu \mathrm{g} / \mathrm{mL}))$. Single colonies were chosen from the plate and streaked separately on an RCA plate with erythromycin $(40 \mu \mathrm{g} / \mathrm{ml})$ to select integrants. The insertion mutants were screened via colony PCR using the primers cac0764del_for and cac0764del_rv (Supplementary Table 2) flanking the target site. The PCR products were purified and confirmed by DNA sequencing. One of the colonies was selected to cure the pMTLO07::cacCA_C0764-408s plasmid and generate MGCAcac1502CA_C0764-408s::CT. This clone was inoculated into Clostridum Growth Medium (CGM) supplemented with erythromycin (40 $\mu \mathrm{g} / \mathrm{mL}$ ) for successive subcultures, as previously described (3). One hundred microliters of fully grown culture was inoculated into $1 \mathrm{~mL}$ of fresh CGM supplemented with erythromycin $(40 \mu \mathrm{g} / \mathrm{mL})$ and grown anaerobically at $37^{\circ} \mathrm{C}$ for at least 12 hours until full growth was achieved. This transfer process was repeated at least 3 times. The last culture was then plated onto a solid RCA plate supplemented with erythromycin $(40 \mu \mathrm{g} / \mathrm{mL})$. Colonies were restreaked successively onto RCA plates supplemented with thiamphenicol $(10 \mu \mathrm{g} / \mathrm{mL})$ and then onto RCA plates supplemented with erythromycin $(40 \mu \mathrm{g} / \mathrm{mL})$. One erythromycin-resistant and thiamphenicol-sensitive clone was selected and inoculated into $3 \mathrm{~mL}$ of SM (7) supplemented with erythromycin $(40 \mu \mathrm{g} / \mathrm{mL})$, grown anaerobically at $37^{\circ} \mathrm{C}$ for at least 24 hours and 
transferred to $30 \mathrm{~mL}$ of $\mathrm{SM}$ supplemented with erythromycin $(40 \mu \mathrm{g} / \mathrm{mL})$. The culture was grown anaerobically at $37^{\circ} \mathrm{C}$ for 7 days until sporulation, and then the spore suspension was stored at $-20^{\circ} \mathrm{C}$. Southern hybridization was finally used to validate the presence of a singleintron insertion into the genome of MGCAcac1502CA_C0764-408s::CT.

A similar approach was applied to yield the MGCAcac1502-gltB181s::CT strain. The insertion mutants were screened using the primers gltB181s direct and gltB181s reverse (Supplementary Table 2) flanking the target site. The PCR products were purified and confirmed by DNA sequencing.

For transformation with $p C L F C A \_C 0764$ and $p C L F$-bcd-etfb-efta, after 5 hours of recovery, cells were plated on RCA medium supplemented with thiamphenicol $(10 \mu \mathrm{g} / \mathrm{mL})$. Single colonies were chosen from the plate and streaked separately on an SM plate with thiamphenicol (10 $\mu \mathrm{g} / \mathrm{ml})$.

For transformation with pCST-LL-CA_CO764 and pCST-LLbcd-etfb-efta, after 5 hours of recovery, cells were plated on RCA medium supplemented with erythromycin $(40 \mu \mathrm{g} / \mathrm{ml})$. Single colonies were chosen from the plate and streaked separately on an SM plate with erythromycin $(40 \mu \mathrm{g} / \mathrm{mL})$.

\section{Supplementary method 4: Southern blot analysis:}

Chromosomal DNA (3-6 $\mathrm{gg}$ ) of both the MGCA1502 and MGCA1502-CA_CO764-408s::CT strains was digested with the HindIII-HF restriction enzyme and loaded on a $0.8 \%$ agarose gel. The transfer was performed in $20 x S S C$ on a nylon membrane. The probe used for hybridization was generated by PCR using ESB universal and ErmB3'- R- F primers (Supplementary Table 2) and then labeled using a DIG High Prime DNA Labeling and Detection Starter Kit II (Roche, 
Mannheim Germany). The protocols for hybridization and detection were performed according to the Roche instructions.

\section{Supplementary method 5: RNA isolation, cDNA synthesis and RT-qPCR analysis:}

After the activation of spores by heat treatment at $80^{\circ} \mathrm{C}$ for $15 \mathrm{~min}$, both MGC $\Delta \operatorname{cac} 1502$ and MGCAcac1502 cac0764-408s::CT strains were cultivated in duplicate in 60-mL glass vials under strict anaerobic conditions at $37^{\circ} \mathrm{C}$ in $\mathrm{SM}$.

When the OD 620 of MGCAcac1502 and MGCAcac1502CA_C0764-408s::CT cultures reached 2.9 and 1.5, respectively, cultures were sampled, immediately frozen in liquid nitrogen and stored at $-80^{\circ} \mathrm{C}$ until use.

Total RNA isolation was performed as previously described (8). Briefly, the frozen sampled cultures were ground promptly in a liquid nitrogen-cooled mortar. RNA was extracted using an RNeasy Midi Kit (Qiagen). Contaminant genomic DNA was then removed using the RNaseFree DNase Set (Qiagen) following the manufacturer's instructions, and the total DNasetreated RNA was then purified and concentrated using an RNA Cleanup Kit (Qiagen). RNA quantification was performed using a NanoDrop ND-1000 spectrophotometer (Labtech France) at $260 \mathrm{~nm}$, and purity was analyzed by determining the $260 \mathrm{~nm} / 280 \mathrm{~nm}$ ratio (purity > 2.1). RNA integrity was also verified on RNA 6000 Nano Chips using an Agilent 2100 Bioanalyzer (Agilent Technologies).

For cDNA synthesis, $1 \mu \mathrm{g}$ of total RNA was used in a $20 \mu \mathrm{L}$ reverse transcription (RT) reaction mixture containing iScript Reverse-transcriptase and a blend of oligo(dT) and random hexamer primers using the iScriptTM cDNA Synthesis Kit (Bio-Rad) according to the manufacturer's instructions. 
Quantitative real-time PCR (qPCR) was conducted with a MyiQ $^{\mathrm{TM}}$ Real Time PCR Detection System (Bio-Rad). Each sample was tested in triplicate in a 96-well plate (Bio-Rad). The reaction mix ( $25 \mu \mathrm{L}$ final volume) consisted of $12.5 \mu \mathrm{L}$ of SsoAdvanced Universal SYBR Green Supermix (Bio-Rad), $2.5 \mu \mathrm{L}$ of the primer pair ( $200 \mathrm{nM}$ final concentration), $2.5 \mu \mathrm{L}$ of $\mathrm{HO}$ and 5 $\mu \mathrm{L}$ of a $1 / 10$ dilution of the cDNA preparation. The absence of possible genomic DNA contamination was checked in each DNase-treated RNA sample. A blank (no template control) was also incorporated in each assay. The thermocycling program consisted of one hold at $95^{\circ} \mathrm{C}$ for $30 \mathrm{~s}$, followed by 40 cycles of $10 \mathrm{~s}$ at $95^{\circ} \mathrm{C}$ and $30 \mathrm{~s}$ at $57^{\circ} \mathrm{C}$. After completion of these cycles, melting-curve data were then collected to verify PCR specificity, contamination and the absence of primer dimers.

The fabZ gene (CA_C3571) was chosen as an internal control (9). The primer pairs fabZf/fabZr, gapCf/gapCr and gapNf/gapNr (Supplementary Table 2) were used to amplify the fabZ, gapC (CA_C0709) and gapN genes (CA_C3657), respectively.

Expression data and associated technical errors were calculated on triplicate experiments using the gene expression module of iQ5 software (Bio-Rad), which uses the model outline on the geNorm website.

\section{References:}

1. Perutka J, Wang W, Goerlitz D, \& Lambowitz AM Use of computer-designed group II introns to disrupt Escherichia coli DExH/D-box protein and DNA helicase genes. J. Mol. Biol. 336:42139 (2004).

2. Heap JT, Pennington OJ, Cartman ST, Carter GP, \& Minton NP. The ClosTron: a universal gene knock-out system for the genus Clostridium. J Microbiol Methods. 70:452-64 (2007)

3. Dusséaux S, Croux C, Soucaille P, \& Meynial-Salles I. Metabolic engineering of Clostridium acetobutylicum ATCC 824 for the high-yield production of a biofuel composed of an isopropanol/butanol/ethanol mixture. Metab. Eng., 18,1-8 (2013). 
4.Croux C, Nguyen NPT, Lee J., Raynaud C. Saint Prix F., Gonzales Pajuelo M., Meynial-Salles I. \& Soucaille P. Construction of a restriction-less, marker-less mutant useful for functional genomic and metabolic engineering of the biofuel producer Clostridium acetobutylicum. Biotechnol. Biofuels. 9, 23 (2016).

5. Caserta, G., Papini, Adamska-Venkatesh, A., Pecqueur, L., Sommer, C., Reijerse, E., Lubitz, W., Gauquelin, C., Meynial Salles I., Pramanik, D., Artero, Atta, del Barrio, M., Faivre, Fourmond, Léger, \& Fontecave, M. Engineering an [FeFe]-Hydrogenase: Do Accessory Clusters Influence $\mathrm{O} 2$ Resistance and Catalytic Bias ? J. Am. Chem. Soc., 140 (16), 5516-5526 (2018).

6. Mermelstein, L.D., Welker, N.E., Bennett, G.G., \& Papoutsakis, E.T., Expression of cloned homologous fermentative genes in Clostridium acetobutylicum ATCC 824. Biotechnology. 10, 190-195 (1992).

7. Girbal L, \& Soucaille P. Regulation of Clostridium acetobutylicum metabolism as revealed by mixed-substrate steady-state continuous cultures: role of NADH/NAD ratio and ATP pool. $J$ Bacteriol 176: 6433-6438 (1994).

8. Yoo M, Bestel-Corre G, Croux C, Riviere A, Meynial-Salles I, \& Soucaille P. A quantitative system-scale characterization of the metabolism of Clostridium acetobutylicum. MBio;6(6):e01808-15 (2015)

9. Jones S.W., Paredes C.J., Tracy B., Cheng N., Sillers R., Senger R.S., \& Papoutsakis E.T. The transcriptional program underlying the physiology of clostridial sporulation, Genome Biol. 9, R114 (2008) 